\title{
Review Article \\ The Synthesis of Nanostructured WC-Based Hardmetals Using Mechanical Alloying and Their Direct Consolidation
}

\author{
N. Al-Aqeeli, N. Saheb, T. Laoui, and K. Mohammad \\ Mechanical Engineering Department, King Fahd University of Petroleum \& Minerals (KFUPM), Dhahran 31261, Saudi Arabia \\ Correspondence should be addressed to N. Saheb; nouari@kfupm.edu.sa
}

Received 26 September 2013; Accepted 9 December 2013; Published 13 February 2014

Academic Editor: Ping Xiao

Copyright ( 2014 N. Al-Aqeeli et al. This is an open access article distributed under the Creative Commons Attribution License, which permits unrestricted use, distribution, and reproduction in any medium, provided the original work is properly cited.

\begin{abstract}
Tungsten carbide- (WC-) based hardmetals or cemented carbides represent an important class of materials used in a wide range of industrial applications which primarily include cutting/drilling tools and wear resistant components. The introduction and processing of nanostructured WC-based cemented carbides and their subsequent consolidation to produce dense components have been the subject of several investigations. One of the attractive means of producing this class of materials is by mechanical alloying technique. However, one of the challenging issues in obtaining the right end-product is the possible loss of the nanocrystallite sizes due to the undesirable grain growth during powder sintering step. Many research groups have engaged in multiple projects aiming at exploring the right path of consolidating the nanostructured WC-based powders without substantially loosing the attained nanostructure. The present paper highlights some key issues related to powder synthesis and sintering of WC-based nanostructured materials using mechanical alloying. The path of directly consolidating the powders using nonconventional consolidation techniques will be addressed and some light will be shed on the advantageous use of such techniques. Cobalt-bonded hardmetals will be principally covered in this work along with an additional exposure of the use of other binders in the WC-based hardmetals.
\end{abstract}

\section{Introduction}

Nanomaterials (defined as being in the size range 1-100 $\mathrm{nm}$ in at least one dimension) have been the subject of extensive research in recent years due to their extraordinary properties over their conventional counterparts. For more than two decades, the topic of nanomaterials' development has been widely investigated by many researchers aiming at exploring their potential and finding suitable applications. Ultimately, they proved to be beneficial in several applications in areas like surface engineering, drug delivery, analytical chemistry, bioencapsulation, as well as in electronic, magnetic, optical, and mechanical devices. It has been stated that they have a remarkable share of the current market ranging close to $\$ 900$ million in 2005 and potentially \$11 billion in 2010 [1]. These figures do stimulate a great deal of research interest amongst institutions and companies aiming at capitalizing on their potential. However, there are still a number of difficulties when it comes to processing of these nanomaterials especially in fabricating final products as these nanomaterials may loss their crystallite size along the path of processing. These problems have to be tackled before the potential of nanoparticles or nanomaterials can be fully realized [1]. The problem of undesirable grain growth is persistent in the sintering/consolidation processes of several advanced materials that usually gain their importance and thus potential properties from their reduced crystallite sizes. The example of tungsten carbide-based cemented alloys will be considered in the upcoming sections to highlight this issue further.

Among advanced materials, tungsten carbide- (WC-) based alloys have been widely used in a range of industrial applications including cutting and drilling tools, wear resistant components in wire drawing, wear resistant surfaces in various parts of equipment, and dies for extrusion and pressing machines; one of the classical examples is WCCo cemented carbides. Their remarkable mechanical properties such as high hardness, excellent high temperature strength, high elastic modulus, good corrosion resistance, and chemical and thermal stability during high temperature 
operations made them commercially very attractive. These mechanical properties are directly dependent on the developed microstructure in the sintered parts which is governed by several factors such as the binder phase content, WC crystallite size, mean free path of the binding phase, and contiguity of WC grains [2-4]. The development of a given microstructure is in turn dictated by the utilized consolidation/sintering process and associated parameters including sintering temperature, time, pressure and atmosphere.

To underline the important research that was devoted to that particular area, one may consider the example of fabricating cemented carbides possessing ultrafine/nanocrystalline WC structure which was the subject of considerable research over the last two decades [5-10]. Traditionally, cemented carbides are produced by liquid phase sintering process carried out above the eutectic temperature of WC-Co (above $1310^{\circ} \mathrm{C}$ ), which often induces undesirable grain growth of the nanocrystalline WC grains during the sintering stage even with the addition of grain growth inhibitors (such as $\mathrm{VC}, \mathrm{Cr}_{3} \mathrm{C}_{2}$, and $\mathrm{Nb}_{3} \mathrm{C}_{2}$ ), which reduce only partially the associated grain growth rate while affecting adversely the strength [11-14]. Alternatively, solid-state processing routes, like in the case of mechanical alloying (MA), are being widely accepted due to the granted advantages of employing this technique. Mechanical alloying has many advantages as a processing technique which includes being simple, versatile, economically viable, and enabling the synthesis of novel alloys, that is, alloying of otherwise immiscible elements. In addition to that, it produces materials with improved properties compared with conventional methods [15].

Alternative modern consolidation/sintering techniques have been developed to eliminate or to drastically reduce the grain growth and thus preserve the nanocrystalline structure of the developed hardmetals. Amongst such techniques are MS (microwave sintering) [16], SPS (spark plasma sintering) also called FAST (field assisted sintering) or PECS (Pulsed Electric Current Sintering) [17-22], PPS (pulse plasma sintering) [23], EDC (electric discharge compaction) [24], and SLS (selective laser sintering) [25]. The common key characteristic of these novel techniques is the sintering process being carried out at lower temperatures and for shorter dwell times compared to the conventional method yet allowing the production of fully dense materials. This is achieved by using dedicated equipment capable of delivering high-intensity pulses to heat up the powder to the desired temperature at high heating rates $150-600^{\circ} \mathrm{C} / \mathrm{min}[22,23]$ and have the process accomplished in a very short time, high-electric pulses like in the cases of SPS/FAST/PPS. The use of modern consolidation techniques in sintering the produced powders is still in its early stage and the area remains fertile particularly in gaining a comprehensive understanding of the associated sintering mechanisms taking place during the short sintering times and the influential factors that govern the diffusion and kinetic processes. Furthermore, the fabrication of actual functional parts followed by appropriate testing to determine their performance is very scarce in the above studies. The present paper addresses a specific class of materials, called hardmetals or cemented carbides, and reviews the recent advances in their related fields. Two key aspects will be discussed, namely, synthesis of nanocrystalline WC-based powders using MA and their direct consolidation methods using nonconventional techniques. The paper also touches upon some possible use of alternative binders other than Co to produce WC-based hardmetals and mechanical properties' evaluation.

\section{Synthesis of Cemented Carbides Using Mechanical Alloying}

Different processing routes were adopted for developing WC-based cemented carbides depending on the desired/ predetermined set of properties. One of the commonly used techniques with promising combination of properties is mechanical alloying (MA) as it was employed in several occasions. It gives the added advantage of producing ultrafine and nanocrystalline products. However, most of the work was done on WC-Co systems and only little attention was given to other binding metallic phases [26].

To highlight some of the previous work in this regard and due to the focus of this paper, the synthesis of nanostructured WC-Co will be mainly considered in this section. This is to underline the successful synthesis of nanostructured WC-Co alloys using MA and the need to adequately consolidate the produced powders to retain the nanostructure in addition to the preferred properties. Previous work will be presented based on the amount of binding material, that is, the increasing amount of $\mathrm{Co}$ and how it affects the microstructure and mechanical properties of the nanostructured alloy. By looking into several research works it appears that the mostly accepted routes for developing WC-Co hardmetals would be by directly milling WC with Co powders, or by milling elemental powders of tungsten, carbon, and cobalt to the desired compositions, or by allowing displacement reactions to take place "mechanochemistry" and yield the desired composition. In the upcoming paragraphs, selected examples of each approach will be presented for some previous work along with the utilized consolidation route.

In the work of Hewitt et al. [27], they directly milled micron-sized WC and Co powders to obtain a nanocomposite powders with a composition of $10 \%$ Co-WC. They studied the effect of milling parameters in an attempt to optimize the process of producing the cemented carbides. In this study, they investigated the effect of milling temperature on the production of nanocomposite WC-10Co powders during mechanical milling. A temperature range from room temperature to $-30^{\circ} \mathrm{C}$ was considered and it was found that milling at room temperature yielded smaller grain sizes (RT: $21 \mathrm{~nm}$ and $-30^{\circ} \mathrm{C}: 26 \mathrm{~nm}$ ). The morphology and size distribution of the resulted nanocomposite powders following milling at different temperatures are shown in the SEM micrographs in Figure 1 . It can be seen that the produced particles at $-30^{\circ} \mathrm{C}$, Figure 1(b), were more refined compared to those produced at room temperature, Figure 1(a). The authors attributed this to the unsaturated welding and fracture mechanisms at $-30^{\circ} \mathrm{C}$ and the progression of transgranular fracture and formation of new grains. Nevertheless, the consideration of higher temperatures could have been more beneficial to study the 


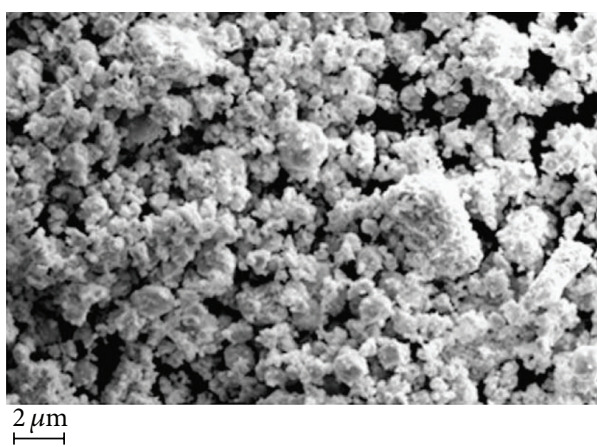

(a)

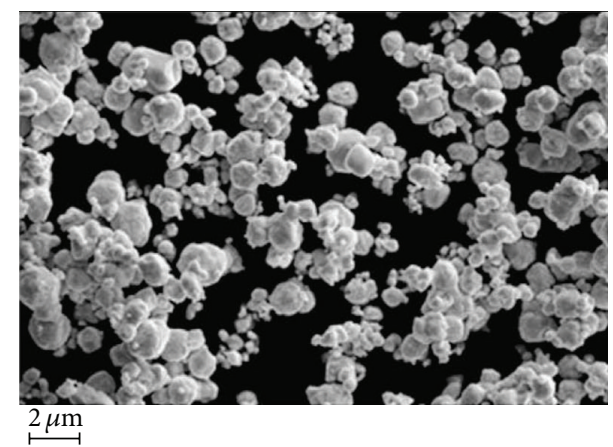

(b)

FIGURE 1: The morphology of the produced nanocrystalline powders of WC-Co processed at different milling temperatures; RT (a) and - $30^{\circ} \mathrm{C}$ (b) (after Hewitt et al. [27]).

effect of higher temperatures on the crystallite size and to touch upon the possible competition between reduction in crystallite size due to the collision forces and the possible grain growth. Moreover, the effect of ball milling time on the production of WC-Co alloys was studied by the same group [28] and it was found that extended milling can lead to finer grain sizes but with higher Fe contamination from the milling medium. These results are rather expected as the possible increase in milling temperature and time can lead to more impact and higher transferred energy to the milled powders which ultimately lead to more damage in the milled powders.

In another similar study conducted by Enayati et al. [29], mechanical alloying was directly implemented to synthesize WC powders with a crystallite size of $15 \mathrm{~nm}$ of direct milling of WC-17 wt.\% Co. It was shown that annealing of the resulting mixture caused a transition from WC phase to undesirable $\mathrm{Co}_{6} \mathrm{~W}_{6} \mathrm{C}$ phase. This underlines the adverse effect of longer annealing times, or higher temperature operations, and the need of nonconventional consolidation techniques that require shorter times. They also compared the synthesis of nanostructured WC by milling of W-C powders versus milling $\mathrm{W}-\mathrm{C}-\mathrm{Co}$ powders.

Direct milling of W-C yielded the nanocrystalline WC whereas milling of elemental powders of W-C-Co did not yield nanosized WC [29]. This highlights an important step in the production of nanostructured WC and proves that milling of WC separately can be of dramatic benefit to possiblly shorten the time needed to form an alloy composed of nanostructured WC. Figure 2 shows the reduction in crystallite size as milling time progresses of W-C mixture. It can be seen that the nanosized regime was reached after milling for as low as $2 \mathrm{hrs}$ of the $\mathrm{W}$-C powders; the starting size of the tungsten powder was $5 \mu \mathrm{m}$ and graphite was about $30 \mu \mathrm{m}$. However, the aforementioned study needs to be complemented by studying the time required to obtain a nanosized WC when W-C-Co powders are being milled. This can be helpful in comparing the two processing routes and preferably relating the milling time to reach nanocrystalline WC with the concentration of Co in the alloy.

In another study [9], the route of separately milling W-C was employed to obtain nanostructured WC and to highlight

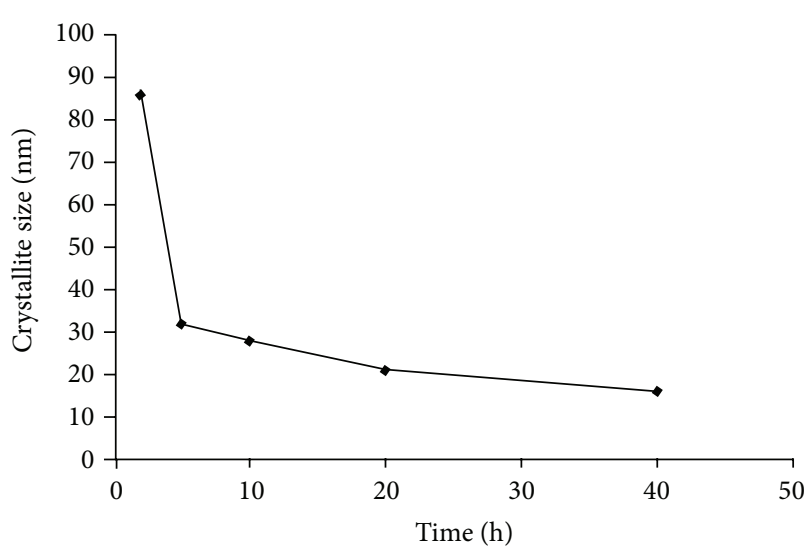

FIGURE 2: Reduction in crystallite size when milling W-C at different time periods (after Enayati et al. [29]).

the effect of prolonged milling times. This was performed to estimate the minimum milling time required to yield nanosized WC and how it relates to the resulted crystallite size. Milling of W-C for time periods exceeding $80 \mathrm{hrs}$ helped in attaining a complete single phase of hcp-WC and the end-product consisted of nanocrystalline grains of less than $5 \mathrm{~nm}$ in diameter. Part of the obtained powders was then milled with different concentrations of Co powders to obtain a nanocomposite. Consolidation of these powders was then performed along with mechanical properties' evaluation. A significant strengthening and increase in elastic modulus due to grain size refinement was observed whereas poor values of fracture toughness were reported. In another study [30], WC-Co cemented carbides were synthesized by in situ reduction and carbonization reactions of metal oxides and carbon using MA. This was followed by a parametric study of the different variables and it was found that the final composition of the powders was significantly influenced by carbon addition in the starting powders, the milling time, the vacuum pressure, and the reaction temperature. Homogeneous structures were found to result following longer milling times, low reaction temperature, and shorter 

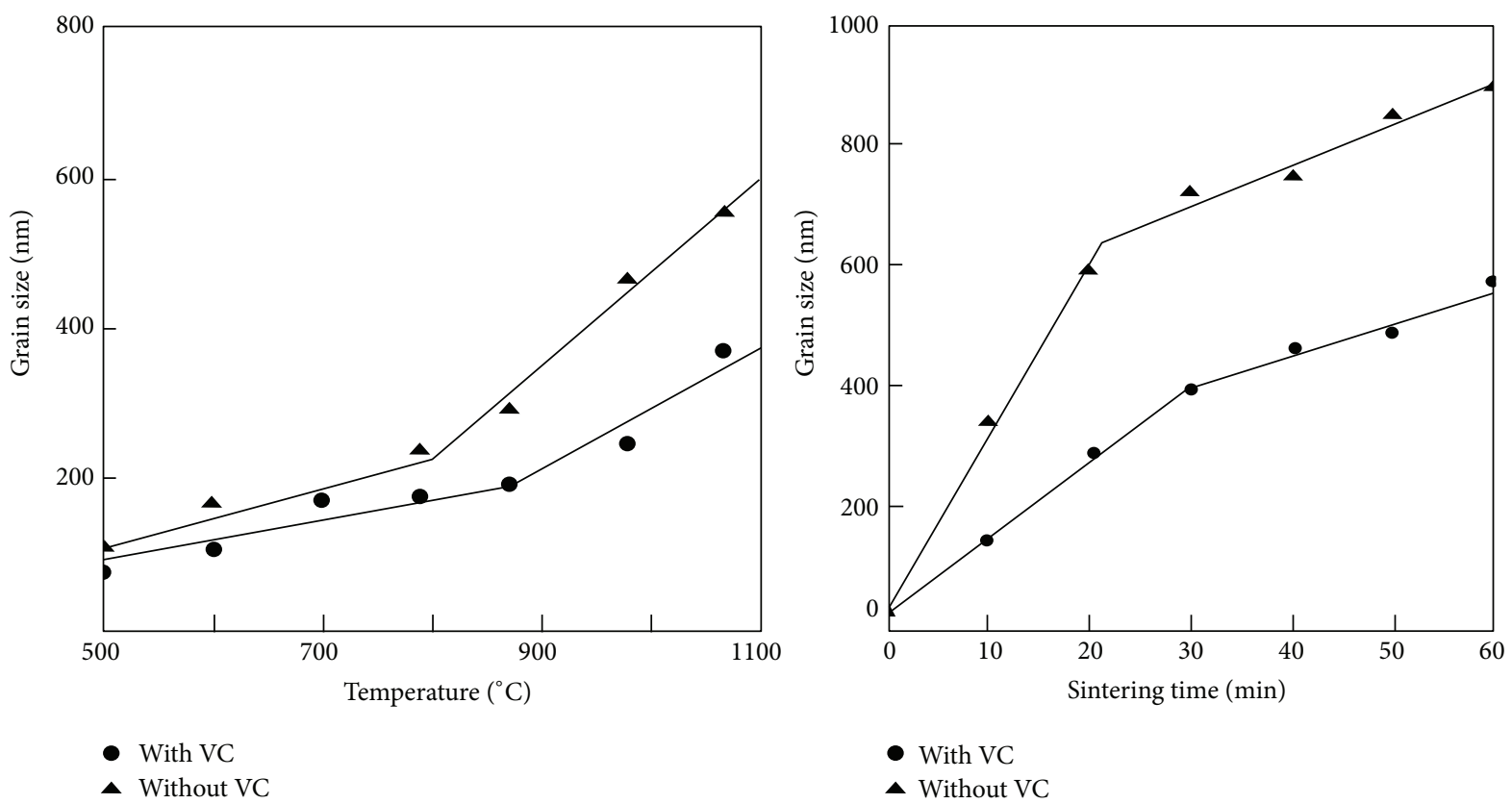

FIGURE 3: The dependence of crystallite size on the annealing temperature and sintering time; this highlights the effect of VC dopant addition, (after Xueming et al. [33]).

holding times [30]. Other routes for the production of WCCo cemented carbides were realized by annealing high energy ball milled $\mathrm{WO}_{3}, \mathrm{CoO}$, and graphite powder mixtures in a hydrogen atmosphere. The authors [31] elaborated on the sequence of transformation of these powders and it was found that $\mathrm{WO}_{3}$ is reduced to $\mathrm{W}$ phase by passing through the intermediate $\mathrm{W}_{20} \mathrm{O}_{58}$ and $\mathrm{WO}_{2}$ phases and they suggested that the subsequent carburization sequence seemed like $\mathrm{W} \rightarrow \mathrm{Co}_{6} \mathrm{~W}_{6} \mathrm{C} \rightarrow \mathrm{Co}_{3} \mathrm{~W}_{3} \mathrm{C} \rightarrow \mathrm{W}_{2} \mathrm{C} \rightarrow \mathrm{WC}$ [31] for the production of WC. In another paper, Xueming and Gang [32] synthesized WC-Co cemented carbides using MA and followed the microstructural evolution using XRD, DSC, and SEM. They concluded that the interdiffusion controlled the formation of the compounds. Compacted samples were tested mechanically and exhibited high hardness values.

By browsing the different directions of synthesizing WCCo nanopowders it seems that the most promising direction is by separately milling $\mathrm{WC}$ and then adding Co in a later stage when the desired crystallite size is reached in the WC; of course this is assuming that the starting powder of WC is in the micron-size due to the low economical viability when starting with nanosized WC. Thus, there remains a question of the appropriate concentration of Co that needs to be added to the WC-based hardmetals and its effect on the formation of a nanostructure and the resulting mechanical properties. It seems that there is no optimum value of cobalt (or other binders) to be added to the WC for enhanced properties. The characteristics of the end product depend primarily on the milling conditions and the subsequent consolidation technique used.

Research directions have also included different addition of impurities to study their possible effect on either retarding grain growth during heat treatments or refining the crystallite size. As for the role of adding grain growth inhibitors, a study by Xueming et al. [33] considered the role of VC as grain growth inhibitor. They employed MA to synthesize two compositions of WC-6 wt.\%Co and WC6 wt.\%Co-1 wt.\%VC starting from elemental powders of tungsten, graphite, cobalt, and vanadium. WC-Co powders with crystalline sizes of about $10 \mathrm{~nm}$ were obtained following MA process. This procedure was followed by compaction and hardness evaluation. They also investigated the effect of $\mathrm{VC}$ content of the resulting powder in particular grain sizes. It was found that the formation of VC was beneficial in retarding grain growth and improving the harness further. Figure 3 highlighted the dependence of crystallite size on the annealing temperature and sintering time and the effect of adding VC dopant to the cemented carbide. It can be seen that the addition of $\mathrm{VC}$ was beneficial in retarding grain growth in the treated alloys. However, the effect of variable addition of VC dopant was not studied in the aforementioned research and a parametric study can possibly lead to solid conclusions about the optimum concentration of dopant.

Furthermore, MA was employed elsewhere [22] to develop cemented carbides based on the compositions of WC-12Co with a crystallite size ranging from 40 to $250 \mathrm{~nm}$. Different grain growth inhibitors were used in this study and consolidation was carried out by spark plasma sintering (SPS) with different additions of $\mathrm{VC}$ and $\left(\mathrm{VC}+\mathrm{Cr}_{3} \mathrm{C}_{2}\right)$. The $\mathrm{VC}$ acted as grain growth inhibitor and combined with SPS the final grain size did not change dramatically. The obtained alloys were compared with those developed via liquid phase sintering and it was found that denser and harder alloys resulted from MA process compared to liquid processing. 


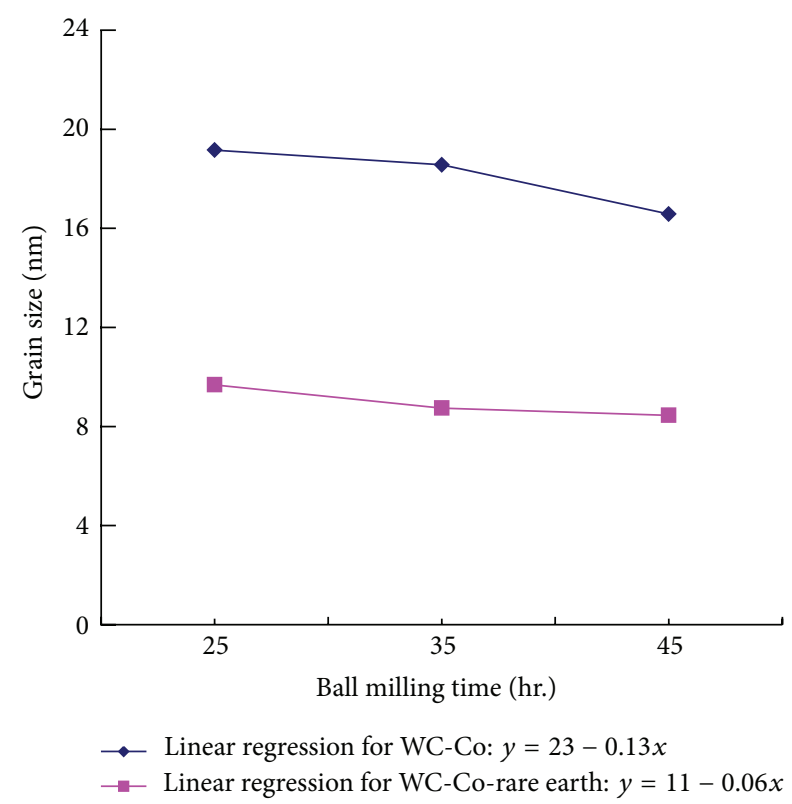

FIGURE 4: Reduction of crystallite size with increasing milling time; the addition of a rare earth was beneficial in reducing crystallite size further (after Liu et al. [34]).

Replacing VC by $\mathrm{Cr}_{3} \mathrm{C}_{2}$ induced further improvement in hardness but with no enhancement in grain growth reduction. As for the role of adding different impurities to the WCCo mixture to obtain a nanocrystalline hardmetals, it was investigated elsewhere [34] and found that small addition of rare earth oxides ( $1.5 \mathrm{wt} . \%$ of $\mathrm{Y}_{2} \mathrm{O}_{3}-\mathrm{La}_{2} \mathrm{O}_{3}-\mathrm{CeO}_{2}$ ) was effective in refining the grain size of WC/Co powder by two times following MA for $25 \mathrm{hrs}$ compared to the undoped alloys Figure 4.

\section{Advanced Consolidation Techniques}

Along with the traditional MA work that focused on developing advanced WC-based hardmetals, there have been equal endeavors aiming at investigating the different venues of improving the quality of the end product by employing several nonconventional consolidation techniques. Some works have focused on combining mechanical alloying with advanced consolidation techniques with the justification that MA yields products with improved properties. Other research dimensions were carried out in different venues of directly consolidating powders of specific sizes and compositions without mechanically milling the powders. This was possibly due to the persisting need of lowering the processing time required to obtain net-shape products which ultimately help in reducing the processing cost. Some highlights of both directions will be considered and whenever possible elaborations will be made on the basis of improved properties and microstructures.

A novel route for synthesizing WC-Co cemented carbides was proposed by Liu et al. [35] which involves an in situ milling reaction followed by SPS consolidation starting from $\mathrm{WO}_{3}, \mathrm{Co}_{3} \mathrm{O}_{4}$, and carbon. These processes resulted in refined and homogenous structure with promising mechanical properties. The authors highlighted the advantages of using such consolidation procedure as it reduces the time and temperature for possible grain coarsening. The fractured surface following consolidation is shown in Figure 5 by SEM and EBSD observations. It can be observed that the WC grains were homogeneously distributed with an average grain size of $0.8 \mu \mathrm{m}$ and little pores as the resulting density was close to $99 \%$. This is in addition to the fact that no preferred crystallographic orientation is resulting by combining these procedures, evident by the EBSD picture. The authors have indicated that the desired structure was obtained at a carbon content of $14.3 \mathrm{wt} . \%$. In the SPS conditions, the reduction reactions need less amount of carbon than the thermodynamic equilibrium, that the gas product is a mixture of $\mathrm{CO}_{2}$ and $\mathrm{CO}$, and that the in situ reactions perform at a rapid speed. Mechanical properties were evaluated and it was found that a good combination of properties was achieved using this method and they are comparable with other conventional sintering techniques. This indicates that the consolidation processes need to be optimized and no receipt-for all can be applied in this type of production.

In another comparative study [36, 37], selective laser sintering (SLS) technique was employed to sinter a hardmetal alloy of the composition WC-9Co and to study the yielded mechanical properties. The authors compared the behavior of powders that were mechanically milled then consolidated with powders that were simply mixed then consolidated. It was found that the resulting green density was higher in mechanically milled powders and the surface quality was improved in the final product due to the previous milling of the powders. They highlighted that by using mechanically milled powders it was challenging to obtain a smooth and uniform layer during powder deposition which precedes the laser sintering technique. Milling can improve the surface roughness even further and can result in very smooth surfaces compared to powders being mixed without milling.

As for the work devoted to developing WC-based hardmetals by direct consolidation without milling, there have been multiple directions proposed with the use of different equipments with variable success. In a study by Kim et al. [38], they implemented two sintering techniques, namely, highfrequency induction-heated sintering (HFIHS) and pulsed current activated sintering (PCAS) for directly consolidating WC- $0,8,10$, and $12 \%$ Co powders. They were able to obtain near theoretical density values, approximately $\sim 99.2 \%$, without considerable change in grain size of the starting powders. It has to be mentioned that the consolidation process was accomplished in 2 minutes and the final product was having a crystallite size of $380 \mathrm{~nm}$.

In another work [39], high-frequency induction heated combustion synthesis (HFIHCS) method was employed in one step to produce WC-5 vol.\% Co materials, with grain size of $\sim 1 \mu \mathrm{m}$ starting from elemental powders of W, C, and cobalt (Co). The process was accomplished within several minutes and it was found that the presence of $5 \mathrm{vol} . \%$ cobalt as a binder improved densification significantly compared to Co-free alloys; density reached $98.5 \%$. Hardness and fracture toughness values were evaluated and it was found 


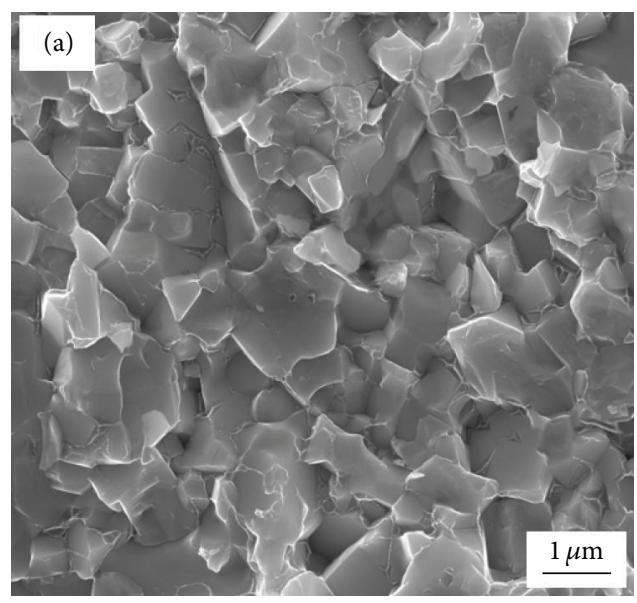

(a)

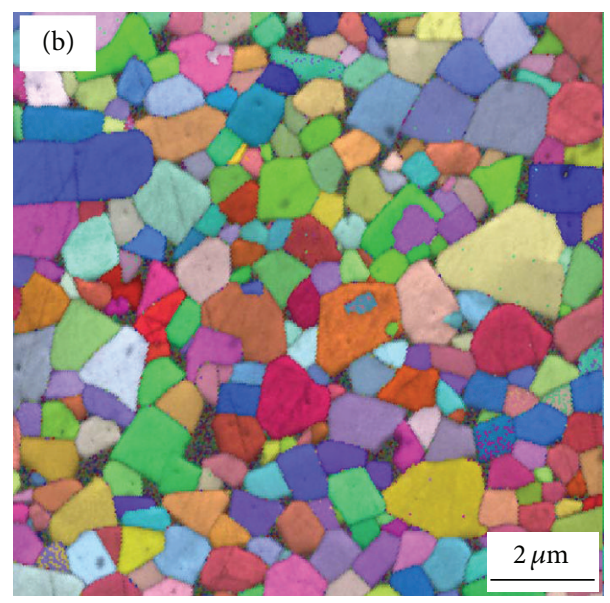

(b)

FIgURE 5: SEM Microstructural observation (a) and EBSD (b) of a fractured surface of the sintered WC-Co alloy (after Liu et al. [35]).

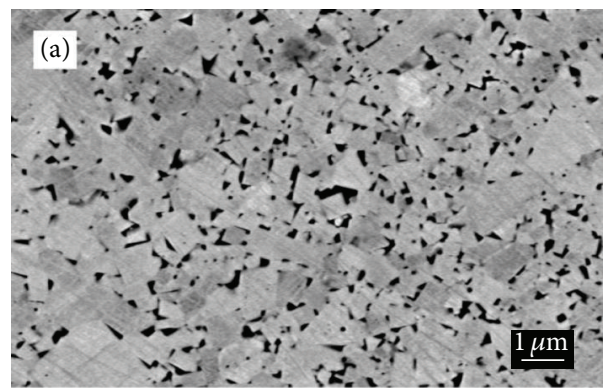

(a)

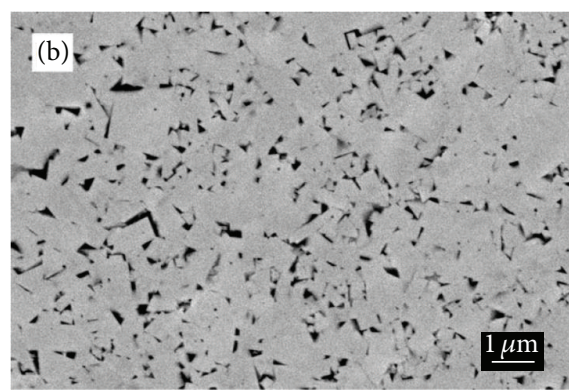

(b)

FIGURE 6: SEM micrographs of the surface of the densified alloys; (a) constant current and $300 \mathrm{~s}$ total time, (b) variable AC current and $180 \mathrm{~s}$ total time (after Deorsola et al. [40]).

that they fall within an acceptable range keeping in mind the easiness of carrying on such quick procedure. In the line of using novel densification techniques, Field Assisted Sintering Techniques (FAST) were used recently by Deorsola et al. [40] to consolidate WC-12Co nanopowders. A novel apparatus was developed belonging to the FAST group which is called Pressure Assisted Fast Electric Sintering (PAFES) and was employed to densify the nanopowders. Fully dense alloys were developed with improved hardness and fracture toughness values. In their parametric study, they compared the effect of applying constant AC current of 1600 over a single sintering cycle of 300 second versus applying a variable current over a sintering cycle of 180 seconds. They studied the microstructure and mechanical properties of the resulted alloys. Figure 6 shows SEM micrographs of the resulting surface and the low concentration of pores can be seen in addition to the refined structure where the crystallite size in the order of few nanometers. They were able also to obtain fully dense alloys with good hardness and fracture toughness values; in the variable current sample the density was close to $100 \%$.

In another study by Kim et al. [41], they introduced a novel high-frequency induction heated sintering (HFIHS) process to rapidly sinter nanostructured hardmetals in a short dwell time. Near theoretical density and prohibition of grain growth in nanostructured materials were the main advantages of using such method. They compared the products of applying pressure on their developed technique with pressureless sintering. A highly dense WC- 15 vol.\%Co was fabricated within $60 \mathrm{~s}$ of processing with an average grain size of $258 \mathrm{~nm}$ and a relative density of $99.4 \%$ was achieved by the application of $60 \mathrm{MPa}$. In the case of pressureless sintering the density was close to $97 \%$ at a sintering time of 200 s. Figure 7 shows SEM micrographs of the final product of the two procedures with and without the application of pressure. It can be seen that when a pressure is applied the product shows less concentration of porosity in addition to the finer structure granted by the reduced sintering time. Mechanical properties such as hardness and toughness were also evaluated but without reference to alloys produced using different techniques. In another work by Liu et al. [42], spark plasma sintering (SPS) was used to introduce a novel route for producing WC-Co by in situ reduction and carbonization reactions of $\mathrm{WO}_{2.9}, \mathrm{Co}_{3} \mathrm{O}_{4}$, and carbon black powders. Using SPS allows for lower temperatures and times compared with other conventional methods. A homogeneous 


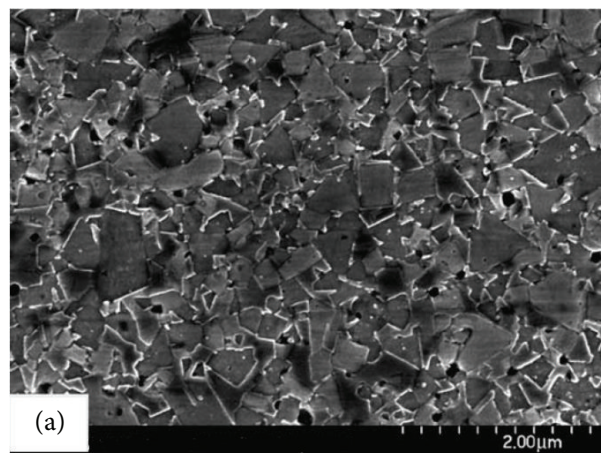

(a)

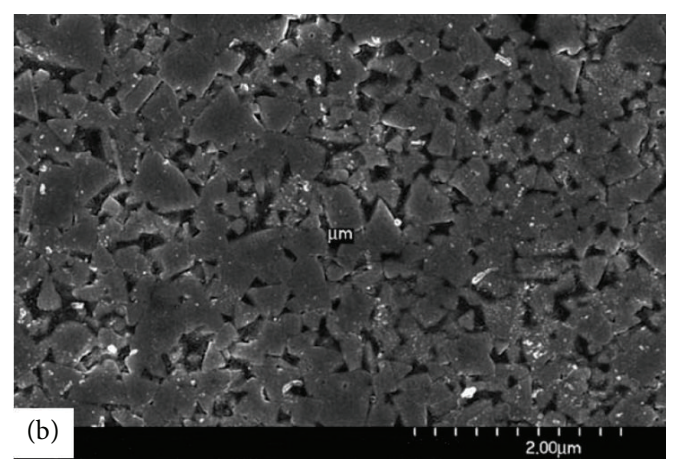

(b)

Figure 7: SEM micrographs of the densified alloys using, (a) $60 \mathrm{MPa}$ and (b) Pressureless sintering (after Kim et al. [41]).

fine-grain microstructure combined with good mechanical properties was achieved using this process.

On the same basis, research efforts have been carried out to explore other dimensions of producing alloys with improved characteristics and enhance the consolidation procedure. In a distinct study [43], graded WC-Co cemented carbides were produced by employing electric-discharge compaction (EDC) of nanocrystalline and coarse WC-Co powders.

On the other hand, some work was found on the use of grain growth inhibitors combined with advanced sintering techniques in order to study the added benefit in reaching refined structures. In this regard, solid state pulsed electric current sintering (PECS) was used by Huang et al. [44] to consolidate WC-12\%Co powders with variable amounts of VC. The addition of VC was beneficial in retarding grain growth, but it was found that higher temperatures are needed to densify the mixture as the content of VC increases. In a different study by Hulyal and Upadhyay [45], the addition of $\mathrm{V}(\mathrm{C}, \mathrm{N})$ was performed to the WC-10Co alloy to study any improvement in properties and grain growth behavior. It was found that this addition was detrimental in terms of densification but has a positive effect on hardness. This is in addition to noticing a considerable grain growth for alloys having an addition of $\mathrm{V}(\mathrm{C}, \mathrm{N})$. This indicates that the addition and possible formation of Vanadium Carbonitride should be avoided as it has an adverse effect on grain growth behavior. In an additional work by the same group, it was shown that an extra addition of Re to the $\mathrm{V}(\mathrm{C}, \mathrm{N})$-WC10 Co did not alter the sintering behavior and properties in the hardmetal containing Vanadium Carbonitride. The only observed improvement was in the hardness of these alloys compared to those without $\operatorname{Re}[46]$.

Other less common novel methods were developed and couple of examples will be included to highlight the fact that multiple efforts were considered. In this regard, a novel technique was developed by Zhonglai et al. [47] using watersoluble salts containing $\mathrm{W}$ and Co as raw materials. They implemented spray-pyrolysis technique for combination of tungsten and cobalt oxide powders $\left(\mathrm{CoWO} / \mathrm{WO}_{3}\right)$ which was then followed by mixing with carbon black and being converted to WC-Co composite powder at $950^{\circ} \mathrm{C}$ for $4 \mathrm{~h}$ in
$\mathrm{N}_{2}$ atmosphere. The procedure has yielded cemented carbides with a particle size of 100-300 nm. Another semiconventional consolidation route was introduced by Kim et al. [38] on the compaction of WC-Co powder using two extrusion stages followed by annealing. Powders of WC-14\%Co composition were compacted using two extrusion steps at $1200^{\circ} \mathrm{C}$ and subsequent annealing in argon at $1400^{\circ} \mathrm{C}$. The fully compacted powders showed acceptable combination of properties which reflect on the usefulness of using such methods for consolidating these cemented carbides. These examples did not consider the use of nonconventional techniques in the production of cemented carbides and they might have their own inherent limitations. Nevertheless, comparative cost and properties analyses can be conducted against other advanced consolidation techniques to have a clearer picture on the use of such techniques as they appear to be cheaper compared to the capital expenditure needed to acquire one of the nonconventional sintering pieces of equipments.

\section{The Use of Other Binders}

It can be seen by browsing the available literature that most of the studied compositions of cemented carbides were dependent on cobalt as a binder and only little work was done on other binding metals like Fe or Ni. It is correct to say that alternative binding metals to cobalt in cemented carbides are less commonly used in engineering applications. This is mainly due to the excellent properties offered by the combination of cobalt and tungsten carbide and the long-lasting successful development of these alloys that met the requirements and/or predetermined properties [48]. In the upcoming paragraphs some light will be shed on the available work on other binders and comparative studies will be discussed aiming at establishing some background on the use of alternative binders and assessing the usefulness of replacing Co. Only studies that have comparative results with Co-bonded cemented carbides will be considered. The comparisons will be based on the quality of the resulting alloys' compacts and the evaluation of their mechanical properties.

One of the early conducted studies was carried out by Almond and Roebuck [49] aiming at identifying the 
best binding material for optimal mechanical properties of the WC-based cemented carbides. Different binder alloys based on $\mathrm{Co}-\mathrm{Ni}, \mathrm{Ni}-\mathrm{Al}, \mathrm{Ni}-\mathrm{Cr}-\mathrm{Mo}$, and $\mathrm{Ni}-\mathrm{Cr}-\mathrm{Mo}-\mathrm{Al}$ were used to develop the hardmetals. It was found that Co and Co-Ni represent the best choices as the developed alloys possessed a good combination of fracture toughness and compressive strains. When $\mathrm{Al}$ was added to the combination it facilitated the formation of $\gamma^{\prime}$ precipitates which raised the strength and conferred creep resistance on the expense of fracture toughness. Another early study by Guilemany et al. [50] was performed on $\mathrm{Co} / \mathrm{WC}$ and $\mathrm{Co}-\mathrm{Ni}-\mathrm{Fe} / \mathrm{WC}$ alloys to investigate the developed microstructure and mechanical properties. As for the microstructure, it was observed that hardmetals with pure cobalt is present in its two allotropic forms, FCC and hexagonal close packed while alloys had a face centered cubic structure when $\mathrm{Co}-\mathrm{Ni}$-Fe were added to the mixture. Mechanical properties such as hardness, compressive strength, and transverse rupture strength of the hardmetals with a cobalt-nickel-iron were slightly lower than those with a cobalt metallic phase for the same tungsten carbide concentration. The fracture toughness values of hardmetals comprising 70-75\% WC and cobalt-nickel-iron metallic phase are higher than those with pure cobalt metallic phase. Most likely the results of the aforementioned studies did not encourage the use of other binders as they were unable to outperform the cemented carbides with Co additions. However, some of the later works were conducted on a similar basis and different results were obtained and in some cases encourage the use of different binders.

Some other studies arrived to the conclusion that the use of different binders still yields the same result or with little improvement. In the work of Shon et al. [51], a comparative study was carried out to evaluate the sinterability of WC with 10 wt.\% of different binders of $\mathrm{Co}, \mathrm{Ni}$, and $\mathrm{Fe}$ using high-frequency induction heated sintering (HFIHS). It was found that similar density, grain sizes of WC, and hardness values were obtained in different binders' situations. As for mechanical properties' enhancement, WC-based hardmetal coatings with different binding metallic phases were developed by Berger et al. [52] using HVOF (high velocity oxyfuel). After mechanical properties' evaluation it was found that the resistance to erosive wear was marginally improved when cobalt was used as binder metal; nevertheless, there was no detected dependence of the wear rate on the type of binder metal.

By continuously browsing the available work on the topic of alternative binders, some studies concluded that the use of alternative binders has an advantageous effect on the obtained mechanical properties. In this regard, a work by Qiao et al. [53] combined mechanical alloying with hotpressing to prepare novel cemented carbides $\left(\mathrm{W}_{0.4} \mathrm{Al}_{0.6}\right) \mathrm{C}_{0.5^{-}}$ Co with different cobalt contents. The authors indicated that the density and operational cost to prepare the proposed novel materials were much lower than those of the WC-Co system.

To investigate the properties of using other binders like $\mathrm{Ni}$ to the cemented carbides coupled with advanced consolidation techniques, the work of Kim et al. [54] considered the

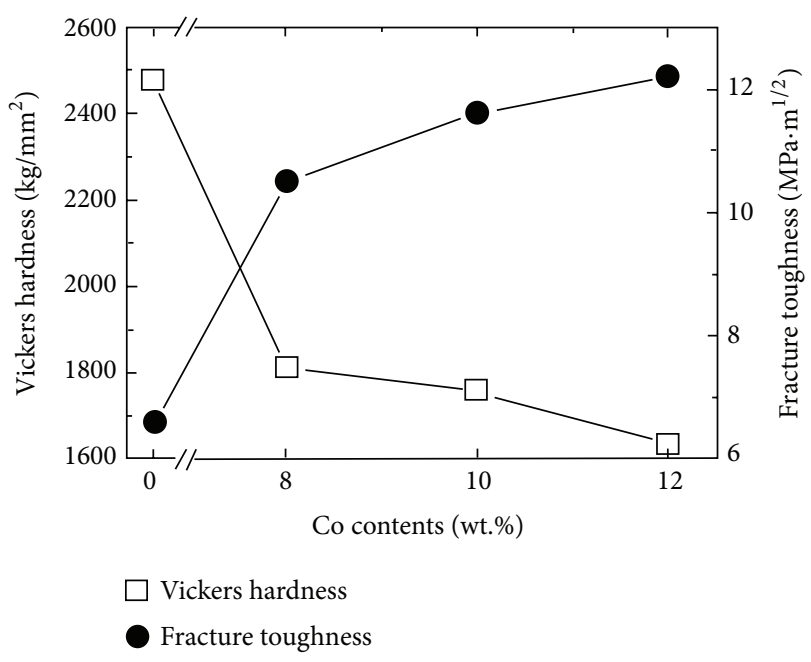

FIgURE 8: Variation of Vickers hardness and Fracture toughness with increasing Co concentration (after Kim et al. [38]).

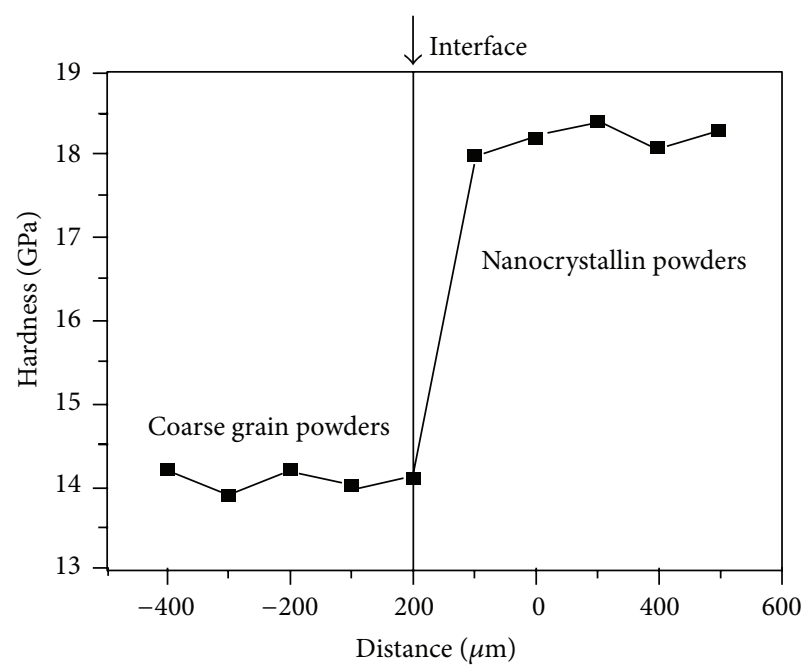

FIGURE 9: Hardness distribution on the graded WC-Co alloy (after $\mathrm{Wu}$ and Guo [43]).

formation of $\mathrm{WC}^{-\mathrm{Ni}_{x}}(x=8,10$, and $12 \mathrm{wt} . \%)$ using highfrequency induction-heated sintering (HFIHS) and compared the results with those obtained for WC-Co hardmetals. Alloys were consolidated to a density of about $98 \%$ and had similar WC grain sizes of $300 \mathrm{~nm}$. Improved hardness values were obtained compared to WC-Co processed through the same route or WC-Ni cermets consolidated using different techniques. Other binding metal combinations were tested elsewhere [55] based on Fe-Mn elements. The main thrust for such research was the continuous sought for cheaper and nontoxic alternatives to cobalt. After mechanical properties' evaluation, it was found that these alloys possess higher hardness and slightly lower fracture toughness values compared to the equivalent compositions and crystallite size of Co-bonded grades [55]. By looking into the previous work on the use of alternative binders, it seems that forming conclusive remarks is far from being possible at this stage. There is a persistent 


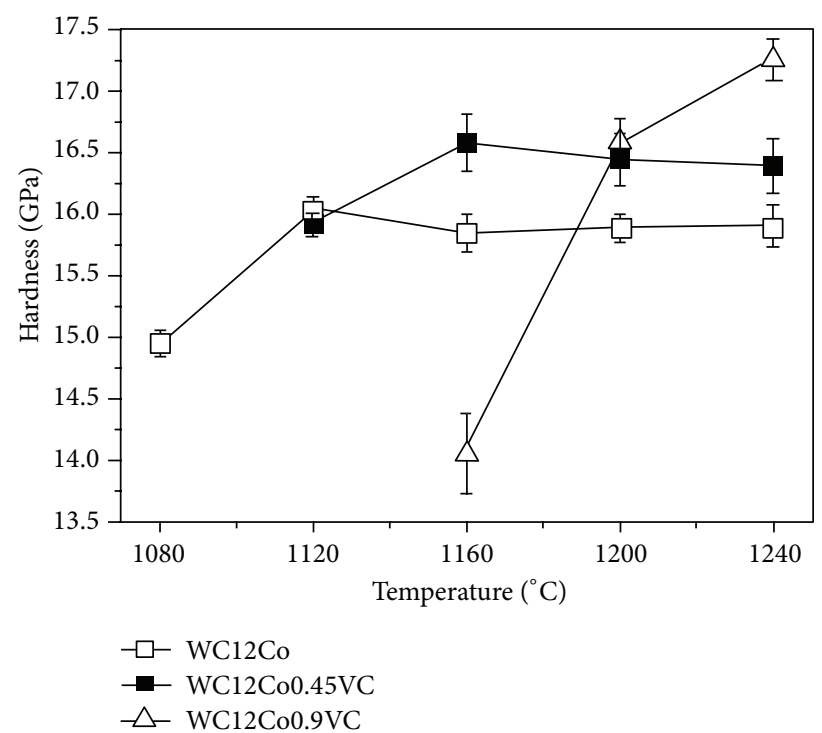

(a)

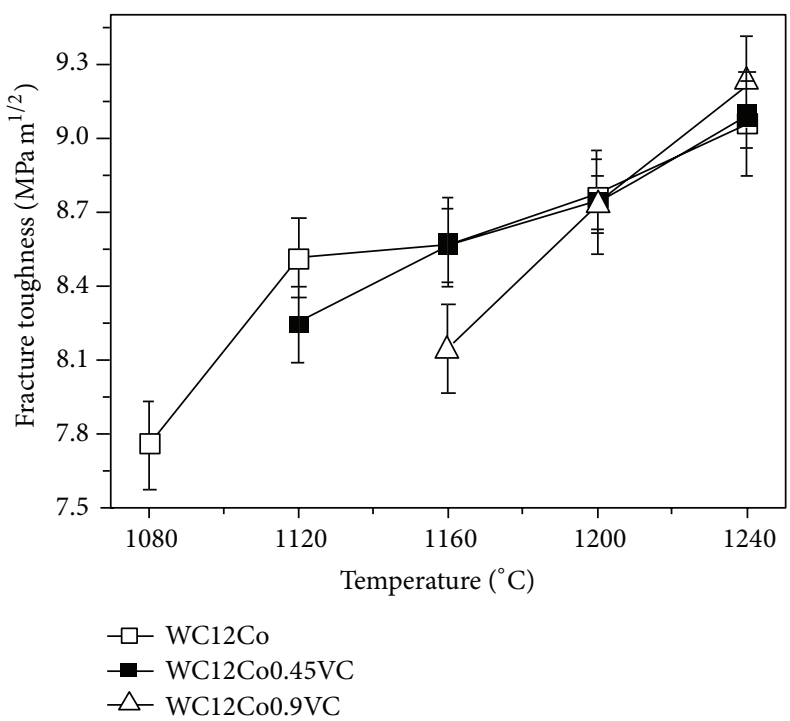

(b)

FIGURE 10: Hardness (a) and Fracture toughness (b) values of for different additions of VC and at different sintering temperatures (after Huang et al. [44]).

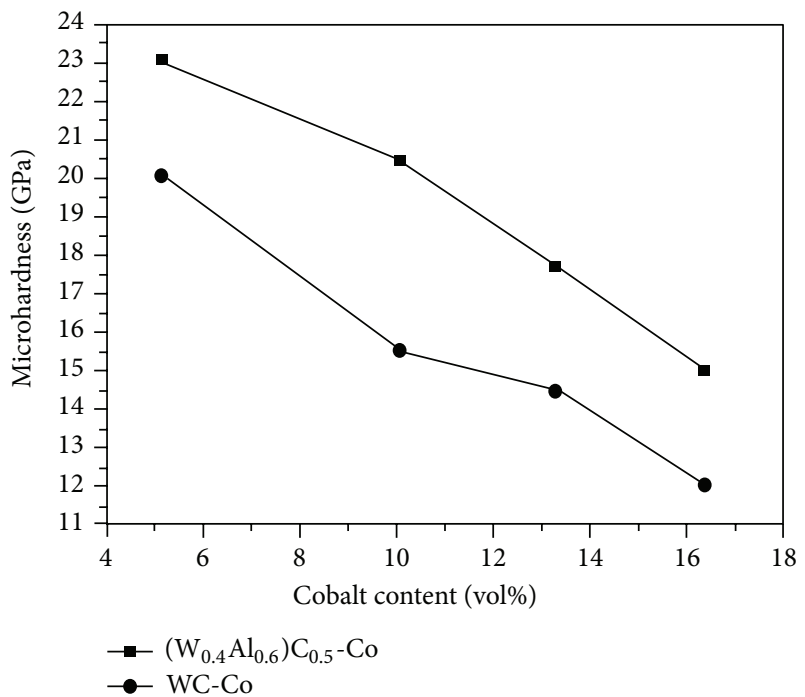

Figure 11: Microhardness values of WC-Co and $\left(\mathrm{W}_{0.4} \mathrm{Al}_{0.6}\right) \mathrm{C}_{0.5}-\mathrm{Co}$ at different Co concentrations (after Qiao et al. [53]).

need for a systematic study that takes multiple factors into consideration while evaluating the use of different binders and conduct comprehensive evaluation of several mechanical properties. This could lead to forming a complete image about the use of Co and other binding materials and possibly clarify the mechanisms that govern the formation of different phases in the final products.

\section{Mechanical Properties' Evaluation}

Mechanical properties of cemented carbides have been the focus of several studies aiming at evaluating the effect of different processing parameters and consolidation routes on the final properties. In this section, only the work related to evaluating the improvement in mechanical properties following the application of several techniques in developing WCCo alloys will be considered. In one of the very early studies, Larsen-Basse [56] evaluated the sliding wear resistance of WC-Co alloys and it was found that preferential removal of Co occurs following the wear tests. Surface evaluation of tested samples showed that the extruded cobalt fragments accumulated as surface defects followed by removal of WC. On a later study by Schaller et al. [57], the internal friction of these cemented carbides was evaluated from room temperature to $1000^{\circ} \mathrm{C}$ for different grades of WC-Co alloys. It was observed that the internal frictions spectrum has a relaxation peak and a high temperature exponential background. At the same temperature range, the peak appears where an increase in toughness has been observed and possible interpretation was due to a brittle-to-ductile transition of the material. A creep phenomenon was keyed to the exponential background with high temperature. The role of the cobalt binder phase in the mechanical behavior of WC-Co was highlighted.

A comparison was carried out earlier by Jia et al. [58] between cemented nanostructured WC-based carbides with conventional microcrystalline ones in terms of microstructure and mechanical properties. It was found that dislocation density was lower in nanosized WC cermets in addition to higher hardness values associated with decreasing mean free path of dislocation in the binder phase. The observed hardness resulted from the presence of ultrafine grains and alloys strengthening by binder. Additionally, toughness was shown to decrease with increase in hardness for conventional alloys while this trend was not observed in nanocrystalline ones. In a very recent study [59], an evaluation for the wear resistance of WC-Co alloys produced using three consolidation 


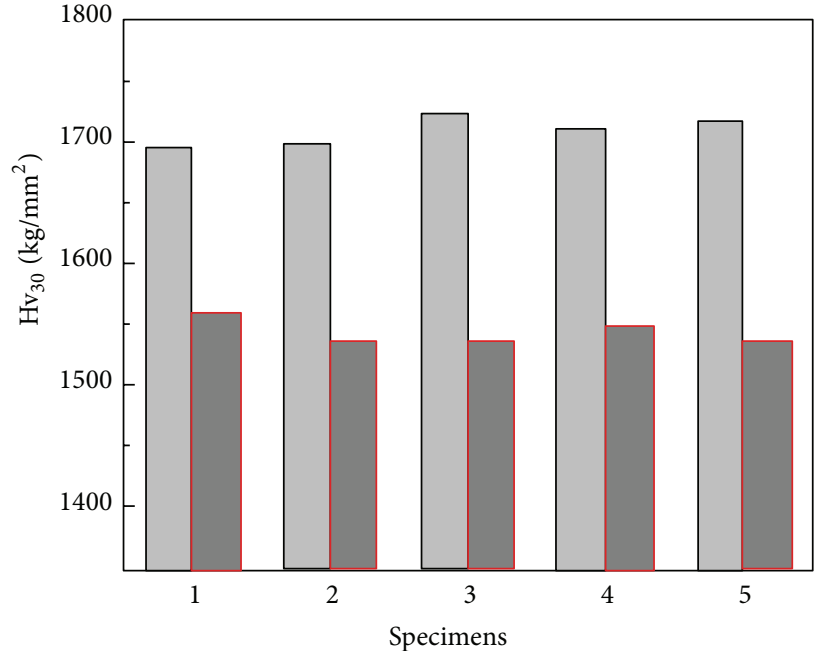

SPS

Sinter-HIP

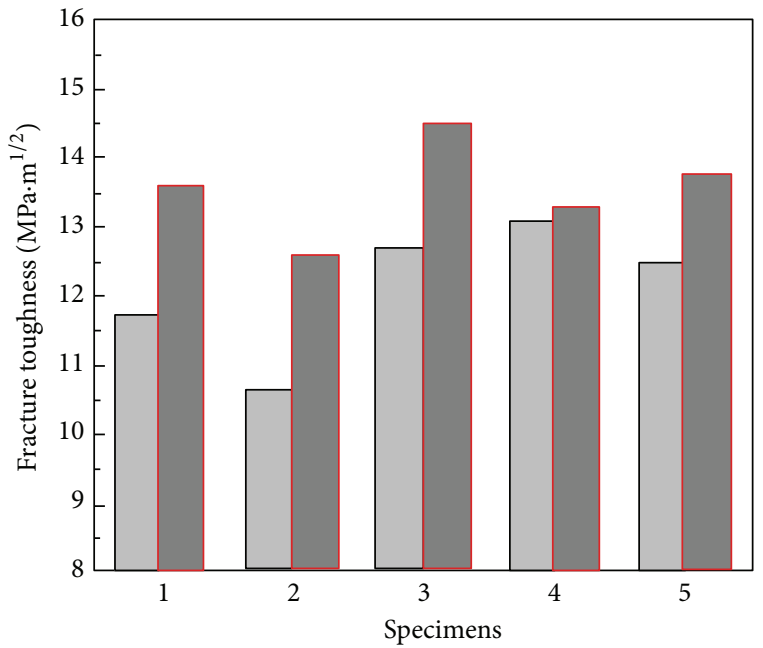

$\square$ SPS

$\square$ Sinter-HIP

(a)

(b)

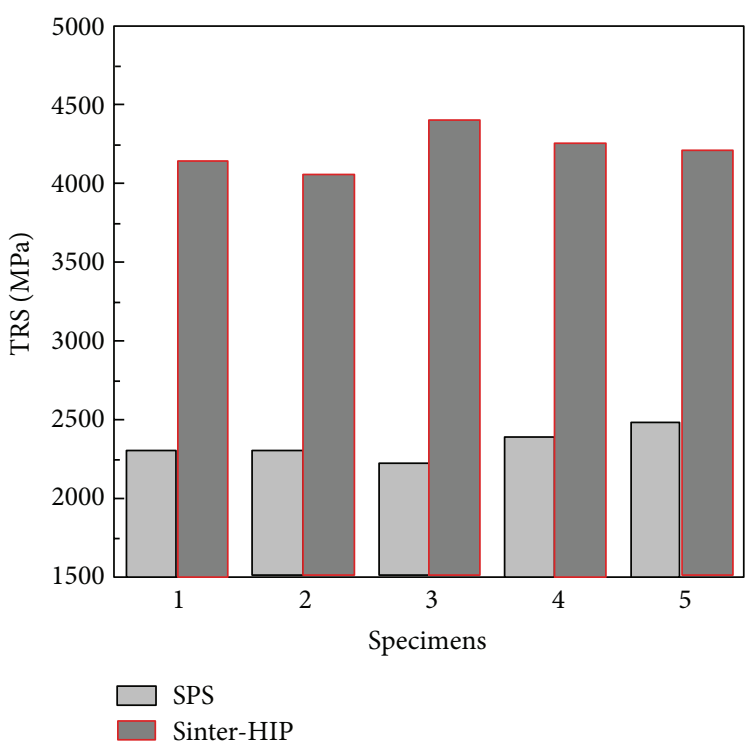

(c)

FIGURE 12: Comparison of mechanical properties of WC-Co bulk specimens prepared by SPS and sinter-HIP: (a) Vickers hardness, (b) fracture toughness, and (c) TR (after Wei et al. [60]).

processing techniques was considered. Tungsten carbideCo coatings were developed using high velocity oxy-fuel (HVOF) spray forming and laser engineered net shaping (LENS), in addition to bulk samples produced using spark plasma sintering (SPS). Hardness values and elastoplastic behavior were determined using ultramicroindentation technique, in addition to wear tests using a tribometer. Low wear rates were observed on alloys produced by all methods due to high densification.

Mechanical properties of WC-0, 8, 10, and 12\%Co hardmetals directly consolidated through high-frequency induction-heated sintering (HFIHS) and pulsed current activated sintering (PCAS) [38] were evaluated and a correlation between fracture toughness and hardness was established in addition to studying mechanical properties' variation with different Co content. This is shown in Figure 8 where it can be seen that the addition of higher binder content has reduced the hardness significantly while improving fracture toughness of the alloys.

Good combination of hardness and toughness was achieved in graded WC-Co cemented carbides [43] produced by employing electric-discharge compaction (EDC) of nanocrystalline and coarse WC-Co powders. This is shown in Figure 9 where there is a remarkable variation in hardness as the measurement crosses from the nanocrystalline to the micron-sized layers. It could be of interest to possibly 
produce alloys with bimodal distribution and study the enhancement in different mechanical properties. However, mixing of different sized powders needs to be correlated with the use of several nonconventional techniques and arrive at solid conclusions on the most beneficial combination of techniques.

Optimal combination of hardness and toughness, as shown in Figure 10, was obtained in WC-12\%Co alloy containing $0.9 \mathrm{wt} . \% \mathrm{VC}$ and consolidated using solid state pulsed electric current sintering (PECS) [44].

Qiao et al. [53] prepared $\left(\mathrm{W}_{0.4} \mathrm{Al}_{0.6}\right) \mathrm{C}_{0.5}$-Co novel cemented carbides with different cobalt contents and showed that this alloy had improved microhardness against WC-Co alloy without $\mathrm{Al}$ addition as shown in Figure 11.

Wei and coworkers [60] characterized and compared the properties of WC-Co cemented carbides produced through spark plasma sintering (SPS) and hot isostatic pressing (sinter-HIP) as representative methods of rapid sintering and liquid-state sintering technologies. The authors reported a $10 \%$ decrease in the hardness and about $80 \%$ increase of the TRS of the material prepared by sinter-HIP compared with the SPSed material as shown in Figure 12. The mean values of hardness of the SPSed and sinter-HIP specimens were $1707 \mathrm{~kg} / \mathrm{mm}^{2}$ and $1543 \mathrm{~kg} / \mathrm{mm}^{2}$, respectively. The mean values of fracture toughness were $12.1 \mathrm{MPa} \mathrm{m}^{1 / 2}$ and 13.6 $\mathrm{MPa} \mathrm{m}^{1 / 2}$, respectively. The mean values of TRS were $4210 \mathrm{MPa}$ and $2337 \mathrm{MPa}$, respectively. The big difference in mechanical properties of the cemented carbides, prepared by the two methods, was attributed to the configuration of WC and Co phases and the WC/Co orientation relationship.

Bulk WC samples containing 7.5 and 12 wt.\% Co were produced, from mechanically alloyed powders, through magnetic pulsed compaction followed by conventional vacuum sintering $[61,62]$. The authors reported that the incorporation of magnetic pulsed compaction prior to sintering yielded a much higher hardness with a maximum value of over $1430 \mathrm{HV}$ for the WC-12 wt.\% Co sample.

Using SPS, Park et al. [63] obtained 100\% dense WC$10 \mathrm{wt} . \%$ Co hard materials with an average grain size of WC of about $270 \mathrm{~nm}$ within 12 minutes at a pressure of $60 \mathrm{MPa}$. The authors reported fracture toughness and hardness values of $25.6 \mathrm{MPa} \cdot \mathrm{m}^{1 / 2}$ and $1755.8 \mathrm{~kg} / \mathrm{mm}^{2}$. In another study, Park et al. [64] produced completely dense WC-10 wt.\% Co hard materials without any significant change in the grain size, from an ultra fine WC-Co powder, using spark plasma sintering by applying a compaction pressure $60 \mathrm{MPa}$ and an electric current for 12 minutes. The average grain size of WC phase was about $0.5 \sim 0.7 \mu \mathrm{m}$. The hardness and fracture toughness values were about $2068.38 \mathrm{~kg} / \mathrm{mm}^{2}$ and $10.21 \mathrm{MPam}^{1 / 2}$, respectively.

Sun el al. [65] used spark plasma sintering to prepare ultrafine grained WC-Co composites containing different amounts of ceria nanoparticles and evaluated their mechanical properties. The authors found that addition of trace of nanoceria particles effectively suppressed the abnormal grain growth of WC and led to uniform and fine microstructures, which resulted in improved hardness and fracture toughness as shown in Figure 13. The hardness and fracture toughness

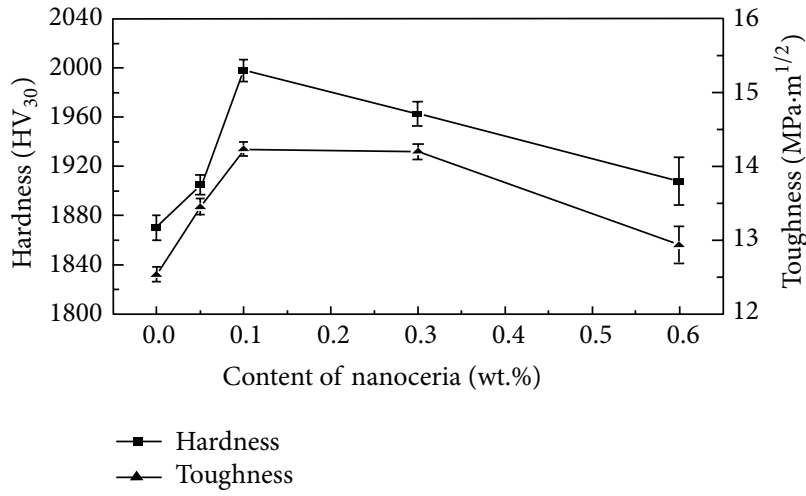

FIGURE 13: Mechanical properties and erosion resistance of ceria nanoparticle-doped ultrafine WC-12Co composite prepared by spark plasma sintering (after Sun et al. [65]).

of the WC-12Co increased by $7 \%$ and $13.4 \%$, respectively, as a result of the addition of $0.1 \mathrm{wt} . \%$ nano-ceria. The improvement in toughness was due to the fact that the finer WC grains deflect cracks more frequently, thus consuming more energy when cracks propagate. However, the authors found that the addition of more than $0.1 \mathrm{wt} \%$ of nanoceria particles lowered the material density, hardness, and toughness, possibly because of the formation of pools of cobalt, which may facilitate the crack propagation.

Mohammad et al. [66] evaluated the influence of powder structure on the mechanical properties of WC-Co hardmetals produced through spark plasma sintering nano- and microcrystalline powders at $1200^{\circ} \mathrm{C}$ for 10 minutes, under an applied pressure of $50 \mathrm{MPa}$ and a heating rate of $100^{\circ} \mathrm{C} / \mathrm{min}$. The authors reported hardness and fracture toughness values of $1625 \mathrm{Hv} 30$ and $13.8 \mathrm{Mpa} \cdot \mathrm{m}^{1 / 2}$, respectively, for the almost fully dense WC-9Co hardmetals. In another study, Al-Aqeeli et al. [67] investigated the effect of temperature and binding material on the mechanical behavior of WC-Co-VC/ $\mathrm{Cr}_{3} \mathrm{C}_{2}$ hardmetals containing 9 and $12 \mathrm{wt} . \%$ produced through ball milling and spark plasma sintering at $1200^{\circ} \mathrm{C}$ and $1300^{\circ} \mathrm{C}$ for $10 \mathrm{~min}$ under high vacuum and pressure of $50 \mathrm{Mpa}$. It was observed that the addition of $\mathrm{VC}$ and $\mathrm{Cr}_{3} \mathrm{C}_{2}$ as grain growth inhibitors decreased the densification of the hardmetals. However, the grain size was about $131 \mathrm{~nm}$. Average values of $1592 \mathrm{H}_{\mathrm{v} 30}$ and $9.23 \mathrm{Mpam}^{1 / 2}$ were reported for the hardness and fracture toughness, respectively. The influence of the type and amount of inhibitors on the mechanical properties of $\mathrm{VC} / \mathrm{Cr}_{3} \mathrm{C}_{2}$ doped WC-Co hardmetals prepared by spark plasma sintering was evaluated in another study by Al-Aqeeli et al. [68]. The authors concluded that adding higher amounts of inhibitors resulted in more restriction to grain growth and led to higher hardness values; however, there was a critical amount beyond which the hardness values decreased.

Analysis of published work showed that spark plasma sintering [69-76] is the dominant technique to consolidate WCbased nanocomposites [18, 22, 35, 42, 59, 60, 63-68, 77-80]. However, processing these composites through other methods, such as selective laser sintering [36, 37], pulsed current activated sintering [38], high-frequency induction heated 


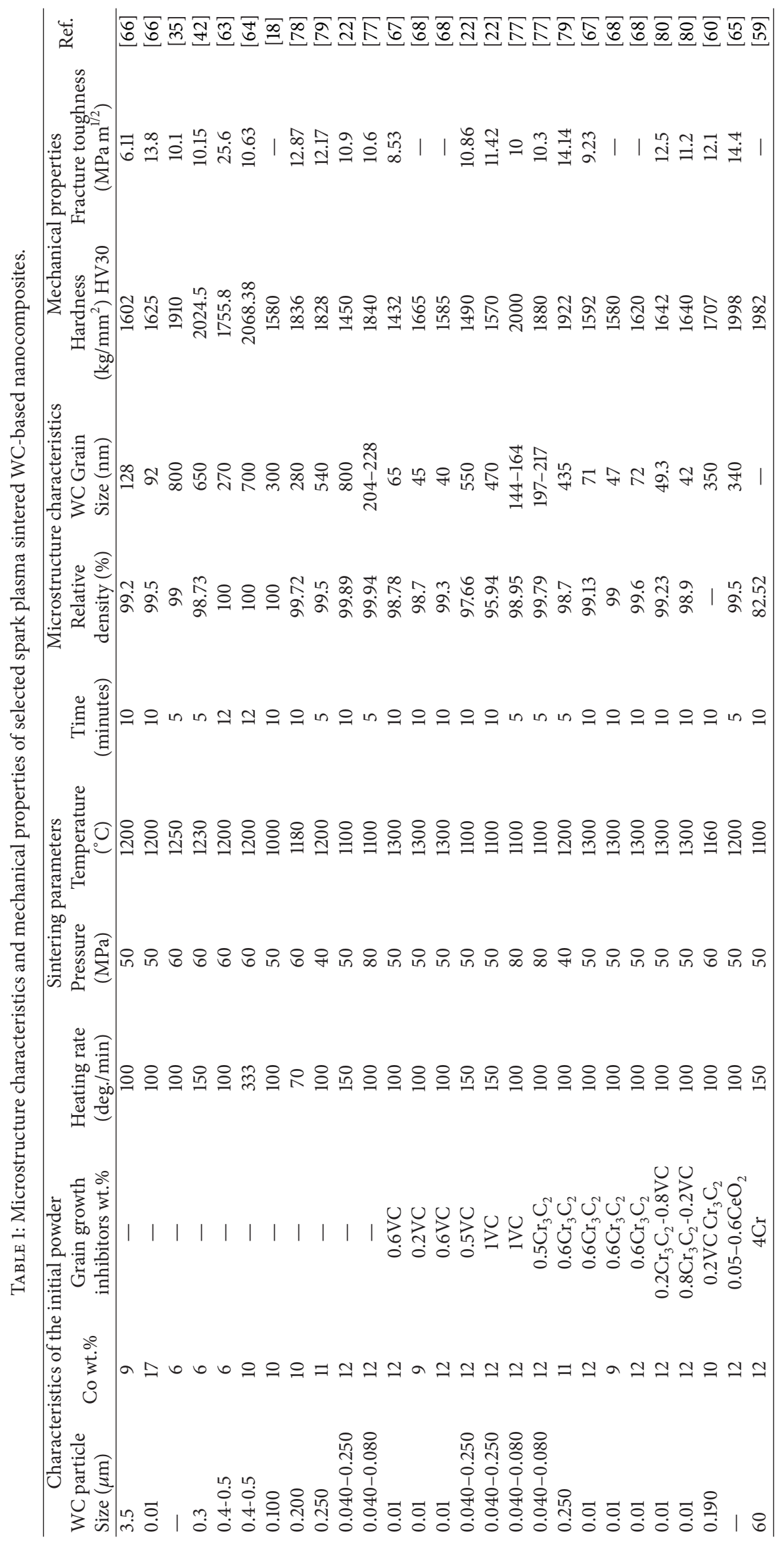


combustion synthesis [39], high-frequency induction-heated sintering [38, 41], electric-discharge compaction [43], pulsed electric current sintering [44], laser engineered net shaping [59], and high velocity oxy-fuel [59], remains an alternative way to produce WC-based nanocomposites with preserved nanostructure and improved properties. Some additional results on microstructure characteristics and mechanical properties of selected spark plasma sintered WC and its composites are presented in Table 1.

\section{Conclusions}

The present work addresses a specific class of materials, WCbased hardmetals or cemented carbides, and reviewed their development using mechanical alloying and their possible production using direct consolidation. The possible use of alternative binders other than Co to produce WC-based hardmetals was addressed along with some mechanical properties' evaluation. The following conclusions can be drawn from the presented review.

(i) Mechanical alloying seems to be a practical choice for processing and developing WC-based cemented carbides due to the inherent advantages of using this technique. By looking into the different options of synthesizing WC-Co alloys using MA it appears that the most promising direction is by separately milling WC and then adding Co in a later stage once the desired crystallite size is reached in the WC. This procedure is applicable for starting powder sizes in the micron-size which reduces the overall cost of development associated with the development path of the WC-based cemented carbides.

(ii) The adequate concentration of the binding metals to yield good combination of properties remains to be explored. A systematic study considering the use of different concentrations and subsequently evaluating their mechanical properties need to be conducted. This is needed to have a proper judgment on the usefulness of using higher or lower concentration of the binding materials and how the properties of the end-product will be affected.

(iii) Spark plasma sintering is the dominant technique to consolidate WC-based cemented carbides. However, other processing methods remain alternative ways to produce WC-based nanocomposites with preserved nanostructure and improved properties.

(iv) The use of advanced consolidation techniques to directly produce WC-based hardmetals seems as a viable option. Comparative cost and properties' analyses have to be conducted between conventional and nonconventional consolidation techniques to have a clearer picture on the use of such techniques; the use of modern consolidation techniques increases the overall cost of alloys' development due to the capital expenditure needed to acquire one of the nonconventional sintering equipments. (v) The use of different dopants to retard grain growth needs to be addressed clearly along with comprehensive evaluation of their effect on mechanical properties. Some researchers have encouraged their use with miniature quantities to avoid adverse effects on mechanical properties; nevertheless, no conclusive remarks can be drawn on the right proportion of dopants.

(vi) The usefulness of using alternative binders to replace Co is far from being convincing at this stage. This is primarily due to the contradicting reports and the lack of a systematic and comprehensive work that takes multiple factors into consideration while evaluating the use of different binders in terms of microstructure and mechanical properties.

\section{Conflict of Interests}

The authors declare that there is no conflict of interests regarding the publication of this paper.

\section{Acknowledgment}

The authors would like to acknowledge the support provided by King Abdulaziz City for Science and Technology (KACST) through the Science and Technology Unit at King Fahd University of Petroleum \& Minerals (KFUPM) for funding this work through project 08-ADV64-4 as part of the National Science, Technology and Innovation Plan.

\section{References}

[1] M. J. Pitkethy, "Nanoparticles as building blocks?" Materials Today, vol. 6, no. 12, supplement 1, pp. 36-42, 2003.

[2] B. K. Kim, G. H. Ha, G. G. Lee, and D. W. Lee, "Structure and properties of nanophase WC/Co/VC/TaC hardmetal," Nanostructured Materials, vol. 9, pp. 233-236, 1997.

[3] W. D. Schubert, H. Neumeister, G. Kinger, and B. Lux, "Hardness to toughness relationship of fine-grained WC-Co hardmetals," International Journal of Refractory Metals \& Hard Materials, vol. 16, no. 2, pp. 133-142, 1998.

[4] C. Allen, M. Sheen, J. Williams, and V. A. Pugsley, "The wear of ultrafine WC-Co hard metals," Wear, vol. 250, no. 1-12, pp. 604-610, 2001.

[5] L. E. McCandlish, B. H. Kear, and B. K. Kim, "Processing and properties of nanostructured WC-Co," Nanostructured Materials, vol. 1, no. 2, pp. 119-124, 1992.

[6] B. H. Kear and L. E. McCandlish, "Chemical processing and properties of nanostructured WC-Co materials," Nanostructured Materials, vol. 3, no. 1-6, pp. 19-30, 1993.

[7] D. F. Corroll, "Sintering and microstructural development in WC/Co based alloys made with super fine WC powder," International Journal of Refractory Metals \& Hard Materials, vol. 17, pp. 123-132, 1997.

[8] B. K. Kim, G. H. Ha, and D. W. Lee, "Sintering and microstructure of nanophase WC/Co hardmetals," Journal of Materials Processing Technology, vol. 63, no. 1-3, pp. 317-321, 1997.

[9] M. S. El-Eskandarany, A. A. Mahday, H. A. Ahmed, and A. H. Amer, "Synthesis and characterizations of ball-milled 
nanocrystalline WC and nanocomposite WC-Co powders and subsequent consolidations," Journal of Alloys and Compounds, vol. 312, no. 1-2, pp. 315-325, 2000.

[10] S. I. Cha, S. H. Hong, G. H. Ha, and B. K. Kim, "Mechanical properties of WC-10Co cemented carbides sintered from nanocrystalline spray conversion processed powders," International Journal of Refractory Metals \& Hard Materials, vol. 19, no. 4-6, pp. 397-403, 2001.

[11] T. Sailer, M. Herr, H.-G. Sockel, R. Schulte, H. Feld, and L. J. Prakash, "Microstructure and mechanical properties of ultrafine-grained hardmetals," International Journal of Refractory Metals \& Hard Materials, vol. 19, no. 4-6, pp. 553-559, 2001.

[12] S. I. Cha, S. H. Hong, G. H. Ha, and B. K. Kim, "Microstructure and mechanical properties of nanocrystalline WC-10Co cemented carbides," Scripta Materialia, vol. 44, no. 8-9, pp. 1535-1539, 2001.

[13] M. Sommer, W.-D. Schubert, E. Zobetz, and P. Warbichler, "On the formation of very large WC crystals during sintering of ultrafine WC-Co alloys," International Journal of Refractory Metals \& Hard Materials, vol. 20, no. 1, pp. 41-50, 2002.

[14] J. Sun, F. Zhang, and J. Shen, "Characterizations of ball-milled nanocrystalline WC-Co composite powders and subsequently rapid hot pressing sintered cermets," Materials Letters, vol. 57, no. 21, pp. 3140-3148, 2003.

[15] C. Suryanarayana, "Mechanical alloying and milling," Progress in Materials Science, vol. 46, no. 1-2, pp. 1-184, 2001.

[16] D. Agrawal, J. Cheng, P. Seegopaul, and L. Gao, "Grain growth control in microwave sintering of ultrafine WC-Co composite powder compacts," Powder Metallurgy, vol. 43, no. 1, pp. 15-16, 2000.

[17] H. Moriguchi, K. Tsuduki, and A. Ikegaya, "Ultrafine grained cemented carbides sintered by pulse current process," Powder Metallurgy, vol. 43, no. 1, pp. 17-19, 2000.

[18] S. I. Cha, S. H. Hong, and B. K. Kim, "Spark plasma sintering behavior of nanocrystalline WC-10Co cemented carbide powders," Materials Science and Engineering A, vol. 351, no. 1-2, pp. 31-38, 2003.

[19] L. H. Zhu, Q. W. Huang, and H. F. Zhao, "Preparation of nanocrystalline WC-10Co-0.8VC by spark plasma sintering," Journal of Materials Science Letters, vol. 22, no. 22, pp. 1631-1633, 2003.

[20] J. R. Groza and A. Zavaliangos, "Nanostructured bulk solids by field activated sintering," Reviews on Advanced Materials Science, vol. 5, no. 1, pp. 24-33, 2003.

[21] X. Wang, Y. Xie, H. Guo, O. van der Biest, and J. Vleugels, "Sintering of WC-Co powder with nanocrystalline WC by spark plasma sintering," Rare Metals, vol. 25, no. 3, pp. 246-252, 2006.

[22] D. Sivaprahasam, S. B. Chandrasekar, and R. Sundaresan, "Microstructure and mechanical properties of nanocrystalline WC-12Co consolidated by spark plasma sintering," International Journal of Refractory Metals \& Hard Materials, vol. 25, no. 2, pp. 144-152, 2007.

[23] A. Michalski and D. Siemiaszko, "Nanocrystalline cemented carbides sintered by the pulse plasma method," International Journal of Refractory Metals \& Hard Materials, vol. 25, no. 2, pp. 153-158, 2007.

[24] X. Y. Wu, W. Zhang, W. Wang et al., "Ultrafine WC10Co cemented carbides fabricated by electric-discharge compaction," Journal of Materials Research, vol. 19, no. 8, pp. 2240 2244, 2004.

[25] X. C. Wang, T. Laoui, J. Bonse, J. P. Kruth, B. Lauwers, and L. Froyen, "Direct selective laser sintering of hard metal powders: experimental study and simulation," International Journal of Advanced Manufacturing Technology, vol. 19, no. 5, pp. 351-357, 2002.

[26] S. Mi and T. H. Courtney, "Synthesis of WC and WC-Co cermets by mechanical alloying and subsequent hot isostatic pressing," Scripta Materialia, vol. 38, no. 1, pp. 171-176, 1997.

[27] S. A. Hewitt, T. Laoui, and K. K. Kibble, "Effect of milling temperature on the synthesis and consolidation of nanocomposite WC-10Co powders," International Journal of Refractory Metals \& Hard Materials, vol. 27, no. 1, pp. 66-73, 2009.

[28] S. A. Hewitt and K. A. Kibble, "Effects of ball milling time on the synthesis and consolidation of nanostructured WC-Co composites," International Journal of Refractory Metals \& Hard Materials, vol. 27, no. 6, pp. 937-948, 2009.

[29] M. H. Enayati, G. R. Aryanpour, and A. Ebnonnasir, "Production of nanostructured WC-Co powder by ball milling," International Journal of Refractory Metals \& Hard Materials, vol. 27, no. 1, pp. 159-163, 2009.

[30] W. Liu, X. Song, J. Zhang, G. Zhang, and X. Liu, "Preparation of ultrafine WC-Co composite powder by in situ reduction and carbonization reactions," International Journal of Refractory Metals \& Hard Materials, vol. 27, no. 1, pp. 115-120, 2009.

[31] Z. G. Ban and L. L. Shaw, "On the reaction sequence of WCCo formation using an integrated mechanical and thermal activation process," Acta Materialia, vol. 49, no. 15, pp. 29332939, 2001.

[32] M. A. Xueming and J. I. Gang, "Nanostructured WC-Co alloy prepared by mechanical alloying," Journal of Alloys and Compounds, vol. 245, no. 1-2, pp. L30-L32, 1996.

[33] M. A. Xueming, J. I. Gang, Z. Ling, and D. Yuanda, "Structure and properties of bulk nano-structured WC-CO alloy by mechanical alloying," Journal of Alloys and Compounds, vol. 264, no. 1-2, pp. 267-270, 1998.

[34] S. Liu, Z.-L. Huang, G. Liu, and G.-B. Yang, "Preparing nanocrystalline rare earth doped WC/Co powder by high energy ball milling," International Journal of Refractory Metals \& Hard Materials, vol. 24, no. 6, pp. 461-464, 2006.

[35] W. Liu, X. Song, K. Wang, J. Zhang, G. Zhang, and X. Liu, "A novel rapid route for synthesizing WC-Co bulk by in situ reactions in spark plasma sintering," Materials Science and Engineering A, vol. 499, no. 1-2, pp. 476-481, 2009.

[36] T. Laoui, L. Froyen, and J.-P. Kruth, "Effect of mechanical alloying on selective laser sintering of WC-9Co powder," Powder Metallurgy, vol. 42, no. 3, pp. 203-205, 1999.

[37] T. Laoui, P. Hespel, J. P. Kruth, and L. Froyen, "Process optimization of WC-9Co parts made by selective laser sintering," in Proceedings of the 8th International Conference on Rapid Prototyping, pp. 419-424, Tokyo, Japan, June 2000.

[38] H. C. Kim, I. K. Jeong, I. J. Shon, I. Y. Ko, and J. M. Doh, "Fabrication of WC-8 wt.\%Co hard materials by two rapid sintering processes," International Journal of Refractory Metals \& Hard Materials, vol. 25, no. 4, pp. 336-340, 2007.

[39] H.-C. Kim, D.-Y. Oh, J. Guojian, and I.-J. Shon, "Synthesis of WC and dense WC-5 vol.\% Co hard materials by highfrequency induction heated combustion," Materials Science and Engineering A, vol. 368, no. 1-2, pp. 10-17, 2004.

[40] F. A. Deorsola, D. Vallauri, G. A. Ortigoza Villalba, and B. D. Benedetti, "Densification of ultrafine WC-12Co cermets by pressure assisted fast electric sintering," International Journal of Refractory Metals \& Hard Materials, vol. 28, no. 2, pp. 254-259, 2010. 
[41] H.-C. Kim, D.-Y. Oh, and I.-J. Shon, "Sintering of nanophase WC-15vol.\%Co hard metals by rapid sintering process," International Journal of Refractory Metals \& Hard Materials, vol. 22, no. 4-5, pp. 197-203, 2004.

[42] W. Liu, X. Song, J. Zhang, F. Yin, and G. Zhang, "A novel route to prepare ultrafine-grained WC-Co cemented carbides," Journal of Alloys and Compounds, vol. 458, no. 1-2, pp. 366-371, 2008.

[43] X. Wu and J. Guo, "Electric-discharge compaction of graded WC-Co composites," International Journal of Refractory Metals \& Hard Materials, vol. 26, no. 1, pp. 28-32, 2008.

[44] S. G. Huang, K. Vanmeensel, L. Li, O. Van der Biest, and J. Vleugels, "Tailored sintering of VC-doped WC-Co cemented carbides by pulsed electric current sintering," International Journal of Refractory Metals \& Hard Materials, vol. 26, no. 3, pp. 256-262, 2008.

[45] R. Hulyal and G. S. Upadhyaya, "Sintering of WC-10 Co hard metals containing vanadium carbonitride and rhenium-part I: vanadium carbonitride addition," International Journal of Refractory Metals \& Hard Materials, vol. 10, no. 1, pp. 1-7, 1991.

[46] R. Hulyal and G. S. Upadhyaya, "Sintering of WC-10 Co hard metals containing vanadium carbonitride and rhenium-part II: rhenium addition," International Journal of Refractory Metals \& Hard Materials, vol. 10, no. 1, pp. 9-13, 1991.

[47] Y. Zhonglai, S. Gangqin, D. Xinglong et al., "Preparation of WC-Co powder by direct reduction and carbonization," China Particuology, vol. 3, no. 5, pp. 286-288, 2005.

[48] B. Uhrenius, H. Pastor, and E. Pauty, "On the composition of $\mathrm{Fe}-\mathrm{Ni}$-Co-WC-based cemented carbides," International Journal of Refractory Metals \& Hard Materials, vol. 15, no. 1-3, pp. 139149, 1997.

[49] E. A. Almond and B. Roebuck, "Identification of optimum binder phase compositions for improved WC hard metals," Materials Science and Engineering, vol. 105-106, no. 1, pp. 237248, 1988.

[50] J. M. Guilemany, I. Sanchiz, B. G. Mellor, N. Llorca, and J. R. Miguel, "Mechanical-property relationships of $\mathrm{Co} / \mathrm{WC}$ and CoNiFe/WC hard metal alloys," International Journal of Refractory Metals \& Hard Materials, vol. 12, no. 4, pp. 199-206, 1994.

[51] I.-J. Shon, I.-K. Jeong, I.-Y. Ko, J.-M. Doh, and K.-D. Woo, "Sintering behavior and mechanical properties of WC-10Co, WC-10Ni and WC-10Fe hard materials produced by highfrequency induction heated sintering," Ceramics International, vol. 35, no. 1, pp. 339-344, 2009.

[52] L.-M. Berger, S. Saaro, T. Naumann et al., "Microstructure and properties of HVOF-sprayed chromium alloyed WC-Co and WC-Ni coatings," Surface and Coatings Technology, vol. 202, no. 18, pp. 4417-4421, 2008.

[53] Z. Qiao, X. Ma, W. Zhao, H. Tang, S. Cai, and B. Zhao, "A novel (W-Al)-C-Co composite cemented carbide prepared by mechanical alloying and hot-pressing sintering," International Journal of Refractory Metals \& Hard Materials, vol. 26, no. 3, pp. 251-255, 2008.

[54] H.-C. Kim, I.-J. Shon, J.-K. Yoon, J.-M. Doh, and Z. A. Munir, "Rapid sintering of ultrafine WC-Ni cermets," International Journal of Refractory Metals \& Hard Materials, vol. 24, no. 6, pp. 427-431, 2006.

[55] C. Hanyaloglu, B. Aksakal, and J. D. Bolton, "Production and indentation analysis of $\mathrm{WC} / \mathrm{Fe}-\mathrm{Mn}$ as an alternative to cobaltbonded hardmetals," Materials Characterization, vol. 47, no. 3-4, pp. 315-322, 2001.

[56] J. Larsen-Basse, "Binder extrusion in sliding wear of WC-Co alloys,” Wear, vol. 105, no. 3, pp. 247-256, 1985.
[57] R. Schaller, J. J. Ammann, and C. Bonjour, "Internal friction in WC-Co hard metals," Materials Science and Engineering, vol. 105-106, no. 2, pp. 313-321, 1988.

[58] K. Jia, T. E. Fischer, and B. Gallois, "Microstructure, hardness and toughness of nanostructured and conventional WC-Co composites," Nanostructured Materials, vol. 10, no. 5, pp. 875891, 1998.

[59] J. A. Picas, Y. Xiong, M. Punset, L. Ajdelsztajn, A. Forn, and J. M. Schoenung, "Microstructure and wear resistance of WCCo by three consolidation processing techniques," International Journal of Refractory Metals \& Hard Materials, vol. 27, no. 2, pp. 344-349, 2009.

[60] C. B. Wei, X. Y. Song, J. Fu et al., "Microstructure and properties of ultrafine cemented carbides-Differences in spark plasma sintering and sinter-HIP," Materials Science and Engineering A, vol. 552, pp. 427-433, 2012.

[61] R. M. Raihanuzzaman, J.-W. Song, and S.-J. Hong, "Evaluation of mechanical properties and processing conditions of WC-Co alloys fabricated by magnetic pulsed compaction," Journal of Alloys and Compounds, vol. 536, supplement 1, pp. S211-S215, 2012.

[62] J.-W. Song, R. M. Raihanuzzaman, and S.-J. Hong, "Consolidation of WC-Co alloys by magnetic pulsed compaction and evaluation of their mechanical properties," Powder Technology, vol. 235, pp. 723-727, 2013.

[63] H.-K. Park, H.-J. Youn, S.-M. Lee, H.-S. Bang, and I.-H. Oh, "Consolidation of ultra fine WC-Co hard materials by a spark plasma sintering method and their mechanical properties," Journal of Ceramic Processing Research, vol. 12, no. 3, pp. 304309, 2011

[64] H.-K. Park, H.-J. Youn, J.-H. Ryu et al., "Fabrication and mechanical properties of WC-10 wt.\% Co hard materials for a friction stir welding tool application by a spark plasma sintering process," Journal of Ceramic Processing Research, vol. 13, no. 6, pp. 705-712, 2012.

[65] X. Sun, Y. Wang, and D. Y. Li, "Mechanical properties and erosion resistance of ceria nano-particle-doped ultrafine WC12Co composite prepared by spark plasma sintering," Wear, vol. 301, pp. 406-414, 2013.

[66] K. Mohammad, N. Saheb, T. Laoui, and N. Al-Aqeeli, "Influence of powder structure on SPS consolidation and mechanical properties of WC-9Co hardmetals," in Proceedings of the 16th International Conference on Advances in Materials and Processing Technologies, Taipei, Taiwan, September 2013.

[67] N. Al-Aqeeli, K. Mohammad, T. Laoui, and N. Saheb, “The effect of variable binder content and sintering temperatures on themechancial properties of WC-Co-VC/ $\mathrm{Cr}_{3} \mathrm{C}_{2}$ nanocomposites," submitted to International Journal of Refractory Metals \& Hard Materials.

[68] N. Al-Aqeeli, K. Mohammad, T. Laoui, and N. Saheb, "VC and $\mathrm{Cr}_{3} \mathrm{C}_{2}$ Doped WC-based Nanocomposites prepared by MA and SPS," submitted to Ceramics International.

[69] N. Saheb, Z. Iqbal, A. Khalil et al., "Spark plasma sintering of metals and metal matrix nanocomposites: a review," Journal of Nanomaterials, vol. 2012, Article ID 983470, 13 pages, 2012.

[70] H. U. Kessel, J. Hennicke, R. Kirchner, and T. Kessel, "Rapid sintering of novel materials by FAST/SPS-Further development to the point of an industrial production process with high cost efficiency," FCT Systeme GmbH, 96528 Rauenstein, Germany, 2012. 
[71] Z. A. Munir, U. Anselmi-Tamburini, and M. Ohyanagi, "The effect of electric field and pressure on the synthesis and consolidation of materials: a review of the spark plasma sintering method," Journal of Materials Science, vol. 41, no. 3, pp. 763-777, 2006.

[72] S. Grasso, Y. Sakka, and G. Maizza, "Electric current activated/ assisted sintering (ECAS): a review of patents 1906-2008," Science and Technology of Advanced Materials, vol. 10, no. 5, Article ID 053001, 2009.

[73] R. Orrù, R. Licheri, A. M. Locci, A. Cincotti, and G. Cao, "Consolidation/synthesis of materials by electric current activated/assisted sintering," Materials Science and Engineering $R$, vol. 63, no. 4-6, pp. 127-287, 2009.

[74] D. M. Hulbert, A. Anders, J. Andersson, E. J. Lavernia, and A. K. Mukherjee, "A discussion on the absence of plasma in spark plasma sintering," Scripta Materialia, vol. 60, no. 10, pp. 835838, 2009.

[75] B. Kieback, "A review of spark plasma sintering," Proceedings of the Hagen Symposium, 2011.

[76] P. Guyot, V. Rat, J. F. Coudert, F. Jay, A. Maître, and N. Pradeilles, "Does the Branly effect occur in spark plasma sintering?" Journal of Physics D, vol. 45, no. 9, Article ID 092001, 2012.

[77] V. Bonache, M. D. Salvador, V. G. Rocha, and A. Borrell, "Microstructural control of ultrafine and nanocrystalline WC$12 \mathrm{Co}-\mathrm{VC} / \mathrm{Cr}_{3} \mathrm{C}_{2}$ mixture by spark plasma sintering," Ceramics International, vol. 37, no. 3, pp. 1139-1142, 2011.

[78] S. X. Zhao, X. Y. Song, C. B. Wei, L. Zhang, X. Liu, and J. Zhang, "Effects of WC particle size on densification and properties of spark plasma sintered WC-Co cermet," International Journal of Refractory Metals \& Hard Materials, vol. 27, no. 6, pp. 1014-1018, 2009.

[79] L. Sun, C. C. Jia, R. J. Cao, and C. G. Lin, "Effects of $\mathrm{Cr}_{3} \mathrm{C}_{2}$ additions on the densification, grain growth and properties of ultrafine WC-11Co composites by spark plasma sintering," International Journal of Refractory Metals \& Hard Materials, vol. 26, no. 4, pp. 357-361, 2008.

[80] N. Al-Aqeeli, "Influence of $\mathrm{VC}$ and $\mathrm{Cr}_{3} \mathrm{C}_{2}$ Codoping on the microstructure and mechanical properties of WC-Co Nanocemented carbides," submitted. 

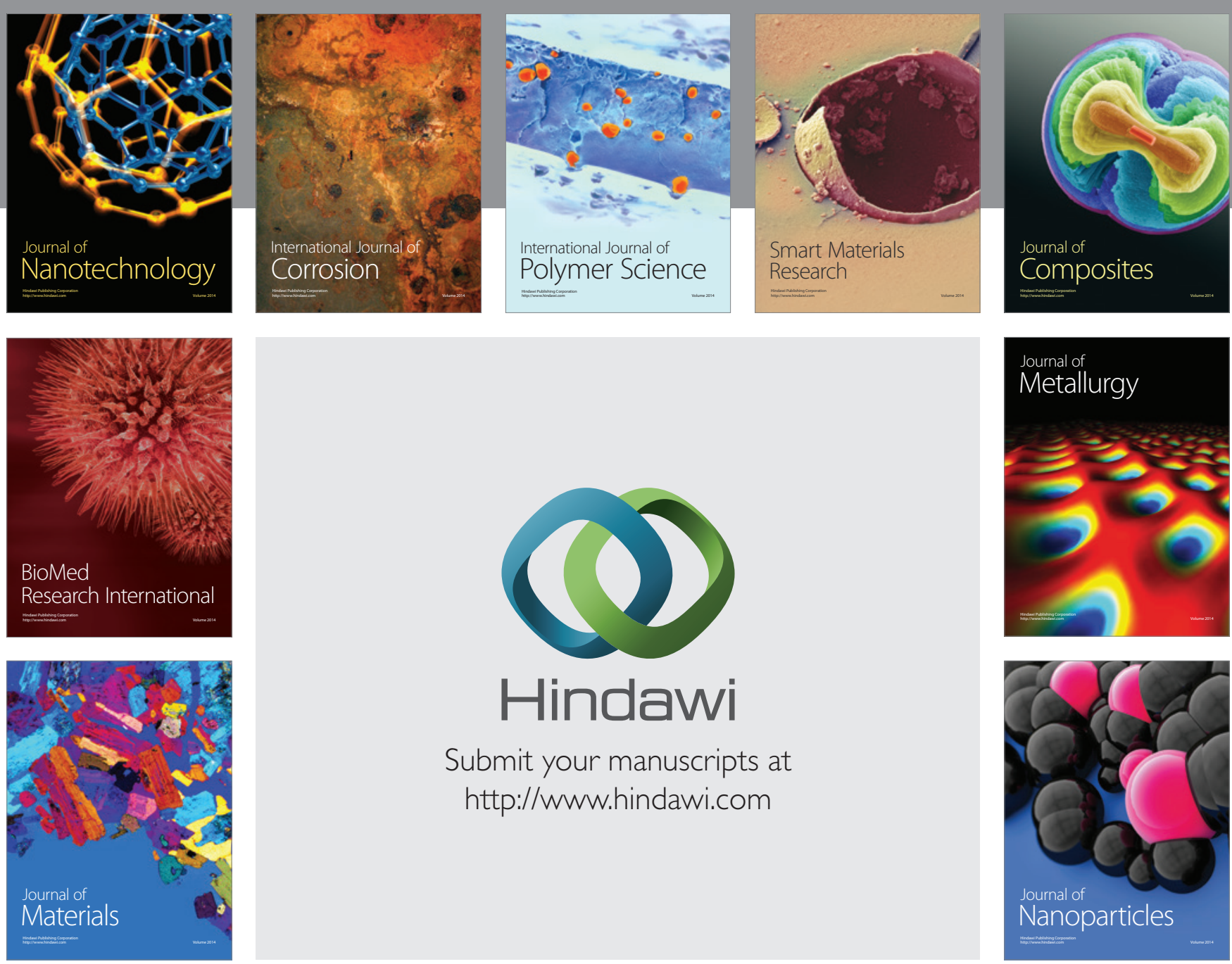

Submit your manuscripts at http://www.hindawi.com
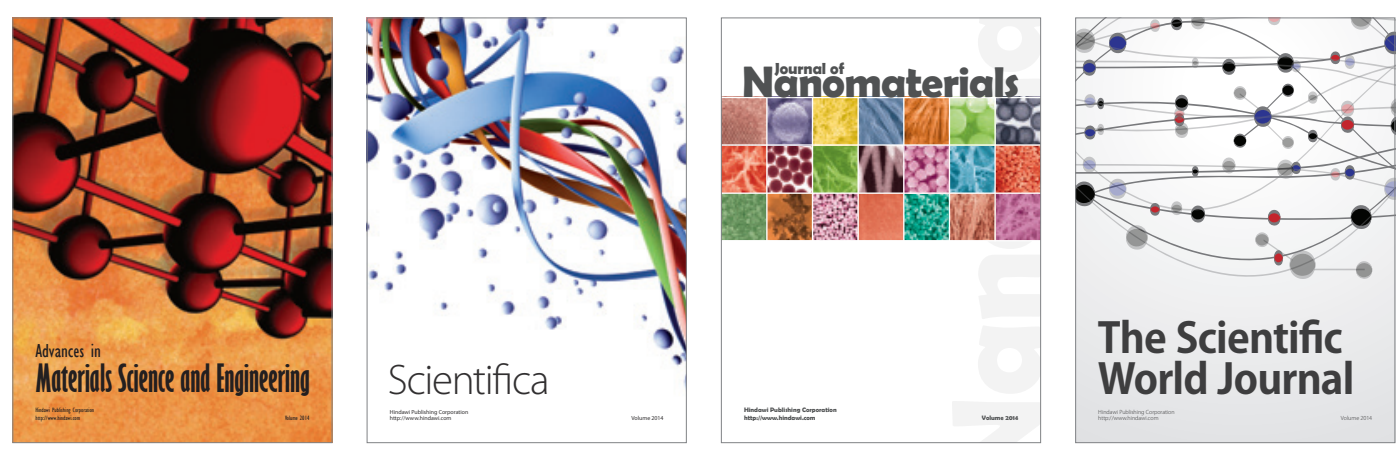

\section{The Scientific World Journal}
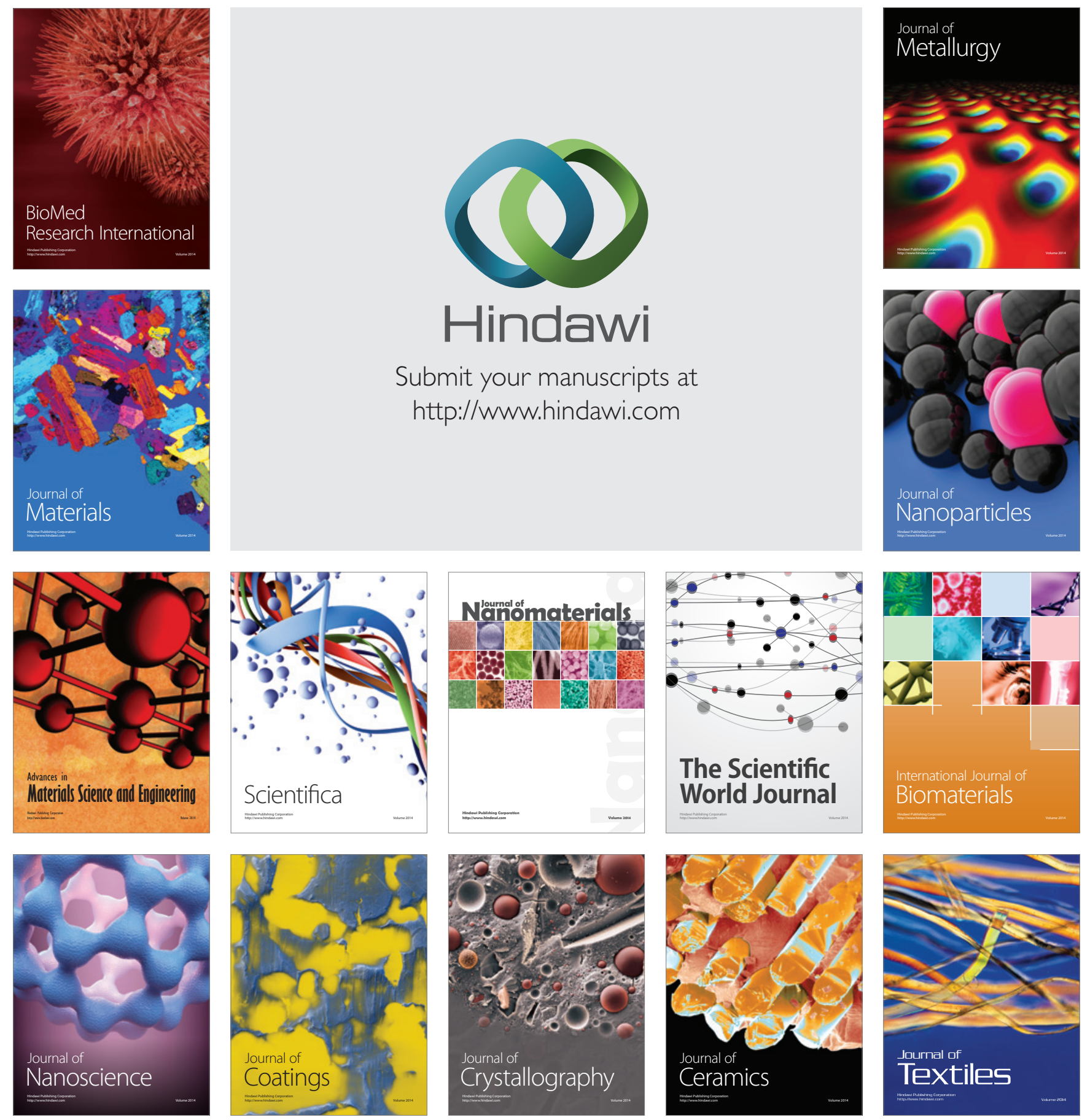